\title{
PHYSICS CALCULATIONS FOR CONTROL RODS IN THE FIRST YANKEE CORE
}

By

William Howard Arnold, Jr.

September 1959

Atomic Power Department

Westinghouse Electric Corporation

Pittsburgh, Pennsylvania

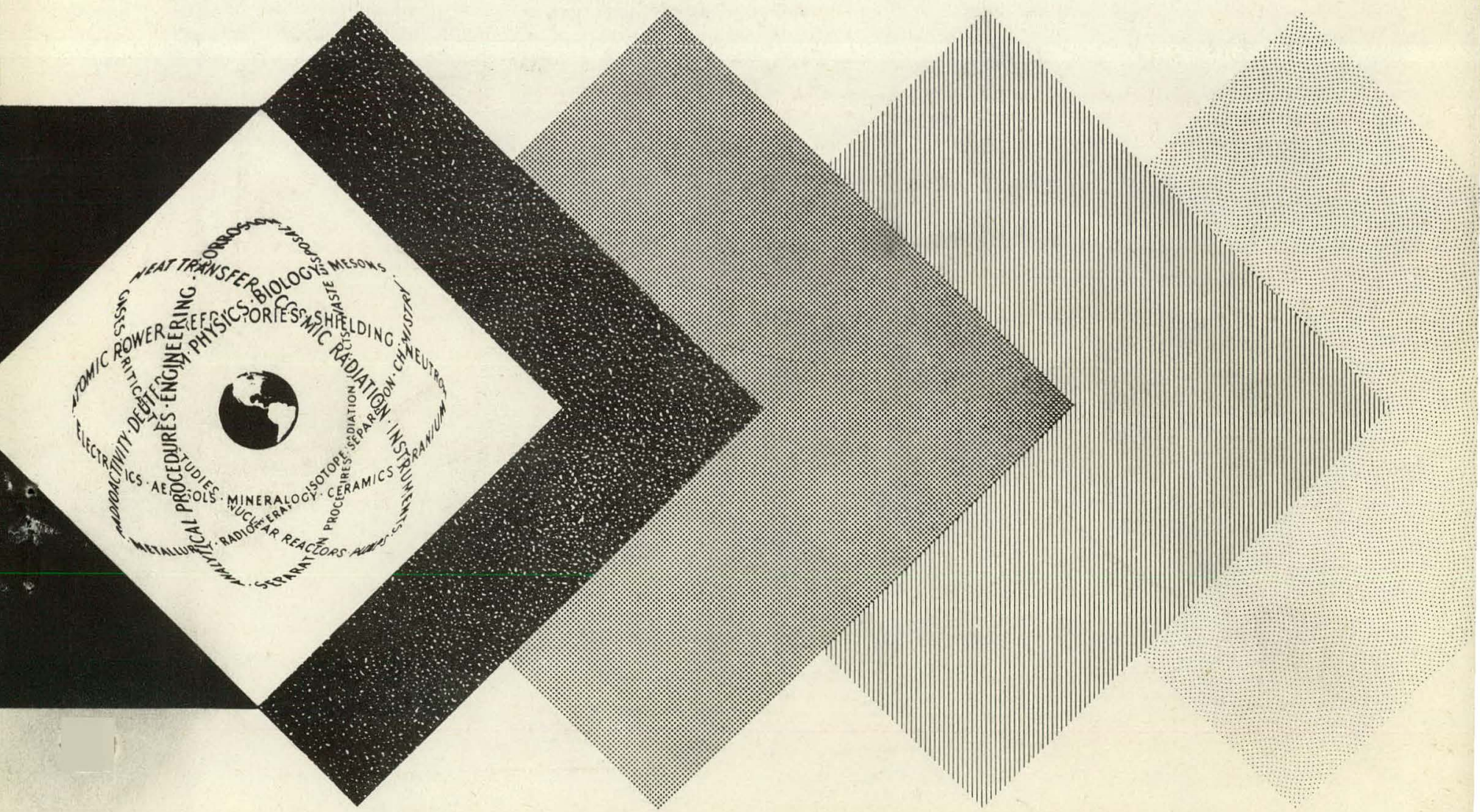




\section{DISCLAIMER}

This report was prepared as an account of work sponsored by an agency of the United States Government. Neither the United States Government nor any agency Thereof, nor any of their employees, makes any warranty, express or implied, or assumes any legal liability or responsibility for the accuracy, completeness, or usefulness of any information, apparatus, product, or process disclosed, or represents that its use would not infringe privately owned rights. Reference herein to any specific commercial product, process, or service by trade name, trademark, manufacturer, or otherwise does not necessarily constitute or imply its endorsement, recommendation, or favoring by the United States Government or any agency thereof. The views and opinions of authors expressed herein do not necessarily state or reflect those of the United States Government or any agency thereof. 


\section{DISCLAIMER}

Portions of this document may be illegible in electronic image products. Images are produced from the best available original document. 


\section{LEGAL NOTICE}

This report was prepared as an account of Government sponsored work. Nelther the United States, nor the Commission, nor any person acting on behalf of the Commission:

A. Makes any warranty or representation, expressed or implied, with respect to the accuracy, completeness, or usefulness of the information contained in this report, or that the use of any information, apparatus, method, or process disclosed in this report may not infringe privately owned rights; or

B. Assumes any liabilities with respect to the use of, or for dsmages resulting from the use of any information, apparatus, method, or process disclosed in this report.

As used in the above, "person acting on behalf of the Commission" includes any employee or contractor of the Commission, or employee of such contractor, to the extent that such employee or contractor of the Commission, or employee of such contractor prepares, disseminates, or provides access to, any information pursuant to his employment or contract with the Commission, or his employment with such contractor.

This report has been reproduced directly from the best available copy.

Printed in USA. Price $\$ 1.50$. Available from the Office of Technical Services, Department of Commerce, Washington 25 , D. C.

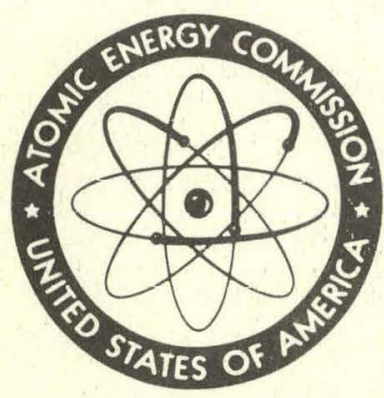




\author{
Yankee Atomic Electric Company \\ Research And Development Program
}

PHYSICS CALCULATIONS FOR CONTROL RODS

IN THE FIRST YANKEE CORE

\author{
Wm. Howard Arnold, Jr. \\ Reactor Development \\ Reactor Analysis Section \\ Reactor Physics Group
}

September 1959

For The Yankee Atomic Electrid Company Under Research and Development Subcontract No. 1 of USAEC-YAEC Contract AT(30-3)-222

A.PPROVED:

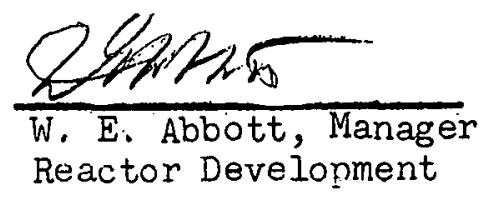

\title{
Westinghouse \\ ECETRIC CORPOAATION ATOMIC POWER DEPARTMENT \\ P.O. BOX 388 \\ PITTEBURGH 30. PA.
}


LIST OF FIGURES. ................. 2

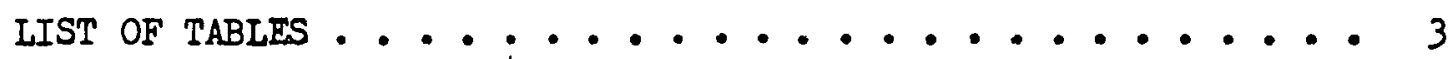

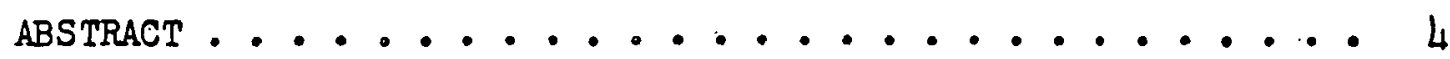

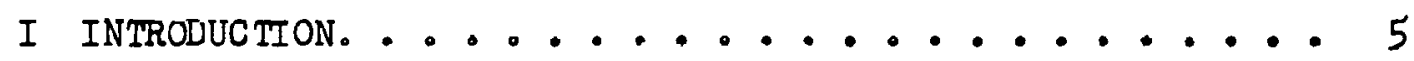

II YANKEE FIRST CORE AND ITS CONTROL REQUIREMENTS. . . . . 7 III THEORY OF CONTROL CALCULATIONS. ........... 13

A. One-Dimensional Calculations........ 15

B. Two-Dimensional Calculations. ....... 20

C. Prediction of $\Sigma_{\mathrm{fCR}} \ldots \ldots . . . . . . .20$

IV EXPERIMENTAL INFORMATION. ........... 26

A. Negative Buckling Measurements....... 26

B. Boron Substitution Measurements ....... 30

C. One-Dimensional Calculations........ 34

D. Two-Dimensional Calculations....... 35

V CALCULATIONS OF THE FIRST YANKEE CORE . . . . . . 37

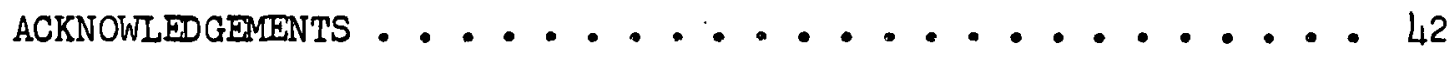

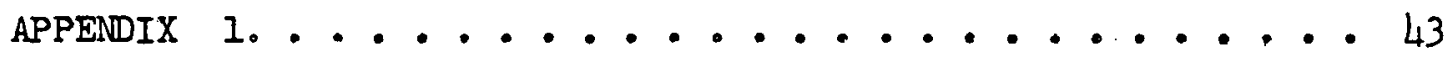

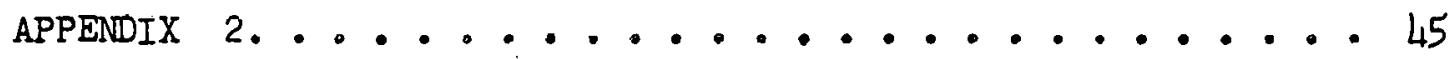
BIBLIOGRAPHY ....................... 47 


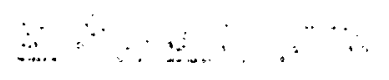

\section{LIST OF FIGURES}

FIGURE

4

5

6

7

8

?

$\because 10$

11
PAGE

Yankee Core Cross Section. . . . . . 8 Yankee Fuel Assemblies. . . . . . . . . 9 Idealizations of Control Rod Super-Cell. . . . 16 Absorptiveness versus Energy" for a .285 inch 70 w. $/ 0$ Ag: - 30 w\% Cd Slab ...... 22

Absorptiveness versus Energy for a .285 inch Slab of $80 \mathrm{w} / 0 \mathrm{Ag}-15 \mathrm{w} / 0 \mathrm{In}$

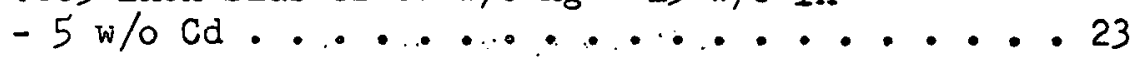

Absorptiveness versus Energy for a .285 inch B-10 Stainless Steel Slab with Various Concentrations of B-10 ......... 24 Top View of Yankee Critical Experiments. . . . 27 Count Rate versus Axial Position, . . . . . 28 Yaukee Critical Experiment:. Ralance of Banked Kod Position Against Boron

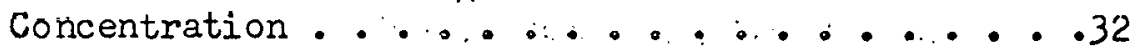
Yankee Control Rod Groups... . . •...... . . 40 Alternate Arrangements of. 24. Control Rods and $8 \mathrm{Zr}$ Fillers in Yankee First Core.................... . . 41 


\section{LIST OF TABLES}

TABLE

PAGE

1

Reactivity Requirements of the First

Yankee Core ................ 11

2

Neutron Constants of the First Yankee

Core. . . . . . . . . . . . . . 12

3

Calculated Values of $\bar{\alpha}$ and $\Sigma_{\mathrm{fCR}} \cdot$. . . . 25 .

4

Negative $B^{2}$ Analysis of Yankee Critical

Experiment Control Rod Worths . . . . . . 29

5

Full Insertion Worths of Control Rods

in Yankee Critical Cores. . . . . . . . . 31

6

Balance of Banked Rod Insertion Versus

Boron Addition ............. 33

7

Deduction of One-Dimensional Fast Neutron

Empirical Absorption Cross Section, $\Sigma_{f C R} \cdot \cdot \cdot 34$

8

One and Two-Dimensional Calculations of

Worths of Rod Rings. . . ....... 36

9

One-Dimensional Calculations of Yankee

Control............. 38

10

Twu-Dimensional Caloulations of Yankep.

Control. 


\section{ABSTRACT}

This report discusses the calculation of control rod worths in light water moderated reactors. Considerable experimental information from the Yankee critical experiments is discussed and applied to improve the theory. The calculation system thus deduced from theory and experiment is then applied to the final design of the first Yankee core to provide a prediction of the shutdown available in its control rods. These calculations show that the 24 control rods presently provided are sufficient to shut the hot, clean, zero power first core down by $3 \%$. 


\section{INTRODUCTION}

The use of $\mathrm{H}_{2} \mathrm{O}$ as a reactor moderator and coolant requires that the fuel be enriched in fissionable material to overcome the neutron absorption by the protons in ordinary water. This in turn means that the core as a whole will be "blacker" (i.e.; have a larger macroscopic absorption cross section, $\Sigma_{a}$ ) than reactors moderated by deuterium, beryllium, or graphite. For example, the $\Sigma_{a}$ of a pressurized water reactor may be in the range of $.1-.2 \mathrm{~cm}^{-1}$ compared to $.02-.05$ for reactors with the other moderators mentioned. This, coupled with the high transport cross section of the water molecule ( 50 - 70 barns), means a very small value of $L$, the thermal diffusion length $\left(=1 / \sqrt{3 \Sigma_{a} \Sigma_{t r}}\right)$. Typical values are from 1 to $3 \mathrm{~cm}$ for pressurized water reactors, while I can range as high as $50 \mathrm{~cm}$ in other reactors. Lowering $L$ has a strong effect on control rod worth because $L$ can be thought of as helping to measure the extent of the region in which a control rod can exert a strong influence. It is often said that $L$ determines how far neutrons can "see". In other words, the smaller I becomes, the smaller is the reactor area controlled by a given size control rod.

Once water has been chosen as a coolant and enriched uranium as a fuel, a fuel element cladding material must be chosen. A number of possible choices exist. All have undesirable and in some cases unknown qualities. Many have faults in corrosion or erosion resistance, metallurgical properties, or cost. Some have problems in their nuclear properties. Stainless steel has extremely good corrosion and erosion properties, has been used and tested more than almost any other material, and its costs are not too high and are well known. However, a pressurized water reactor with stainless steel cladding will have an $L$ which is lower than given by other possible clads. In such a reactor it may be necessary to supplement the control rods with chemical poison dissolved in the water (e.g., boric acid) in order to provide cold shutdown. This disadvantage is not, of course, sufficiently strong to overcome the cost savings and reliability which accrue from the extreme simplicity and compactness of this reactor type. 
Indeed, the ability to so readily use a soluble poison could be a great advantage if one were allowed to use it at power.

The $\mathrm{L}^{2}$ on Yankee is such that the absorption of thermal neutrons only by the 24 control rods is insufficient to shut the core down hot. Thus, if the control rods absorbed only thermal neutrons, it would be necessary to provide some soluble poison shim control at power. However, most control rod materials absorb an appreciable amount of epithermal neutrons. Hafnium, silver, indium, and some of the rare earth materials have a wealth of absorption resonances. Even boron-10, with a straight $1 / v$ cross section can be put in a control rod in a concentration large enough to provide substantial epithermal absorption. In addition, an appreciable portion of the neutron energy spectrum in the Yankee Reactor is above the thermal neutron energy level. These two factors substantially increase the effectiveness of the control rods.

Before one can discuss the amount of control provided by the various means of absorbing neutrons, it is necessary to be aware of how much control is needed, and why. Section II discusses the first Yankee core and its control requirements. Following it. are sestiono dcalinis wllu lue theory of control calculations and the experimental data obtai ned from the Yankee critical experiments. Section $V$ returns again to a discussion of the first Yankee core and applies the methods discussed to the final design. 
II. YANKEE FIRST CORE AND ITS CONTROL REQUIREMENTS

Figure 1 is a cross sectional drawing of the Yankee pressure vessel, thermal shields, and core. The 76 fuel assemblies, enclosed by the steel baffle to channel the flow of coolant, are of two types shaped in such a way as to leave 32 slots in which cruciform absorber elements or nonabsorbing fillers can be placed. Since only 24 control rod mechanisms will be provided for the first core, eight of the slots will have to contain fixed fillers. These 8 fillers can be either absorbing or nonabsorbing. Both alternatives will be available and the decision of which set to put in will be made at the site as the last chance to shim the core in case the reactivity of the hot, clean core proves higher than anticipated. This will be discussed in Section $V$ below. Figure 1 shows these fillers grouped in pairs at the flat faces of the core, but the possibility of varying this arrangement is also discussed in Section $V$.

Figure 2 shows the two types of assembly, and their associated control rod, in greater detail. The fuel is $\mathrm{UO}_{2}$ enriched to $3.4 \mathrm{w} / \mathrm{o}$ U-235. The control rod itself is twice as long as the fuel. One half is absorber; the other, a zircaloy follower to minimize flux peaking and flow short-circuiting when the absorber is withdrawn upward. The absorber material is nominally a silver-indium-cadmium ( $80 \% \mathrm{Ag}, 15 \% \mathrm{In}$, $5 \% \mathrm{Cd}$ ) alloy but, at least from the physics standpoint, could be hafnium, stainless steel with at least $1.2 \mathrm{w} / 0$ boron-10, or various rare earth cermets.

Calculations, based upon critical experiment results (presented in Section $V$ of this report) indicate that the 24 control rods provided will not be sufficient to hold down the cold, clean core. Indeed, the provision of rods in all 32 locations would be unable to do this. To provide additional shutdown in any desired amount, a system has been added to the plant to allow a soluble neutron poison, such as boric acid, to bc added to or removed from the coolant water. As a matter of fact, it can be shown easily that the soluble poison system involves considerable cost savings over the alternate core which has sufficient control 


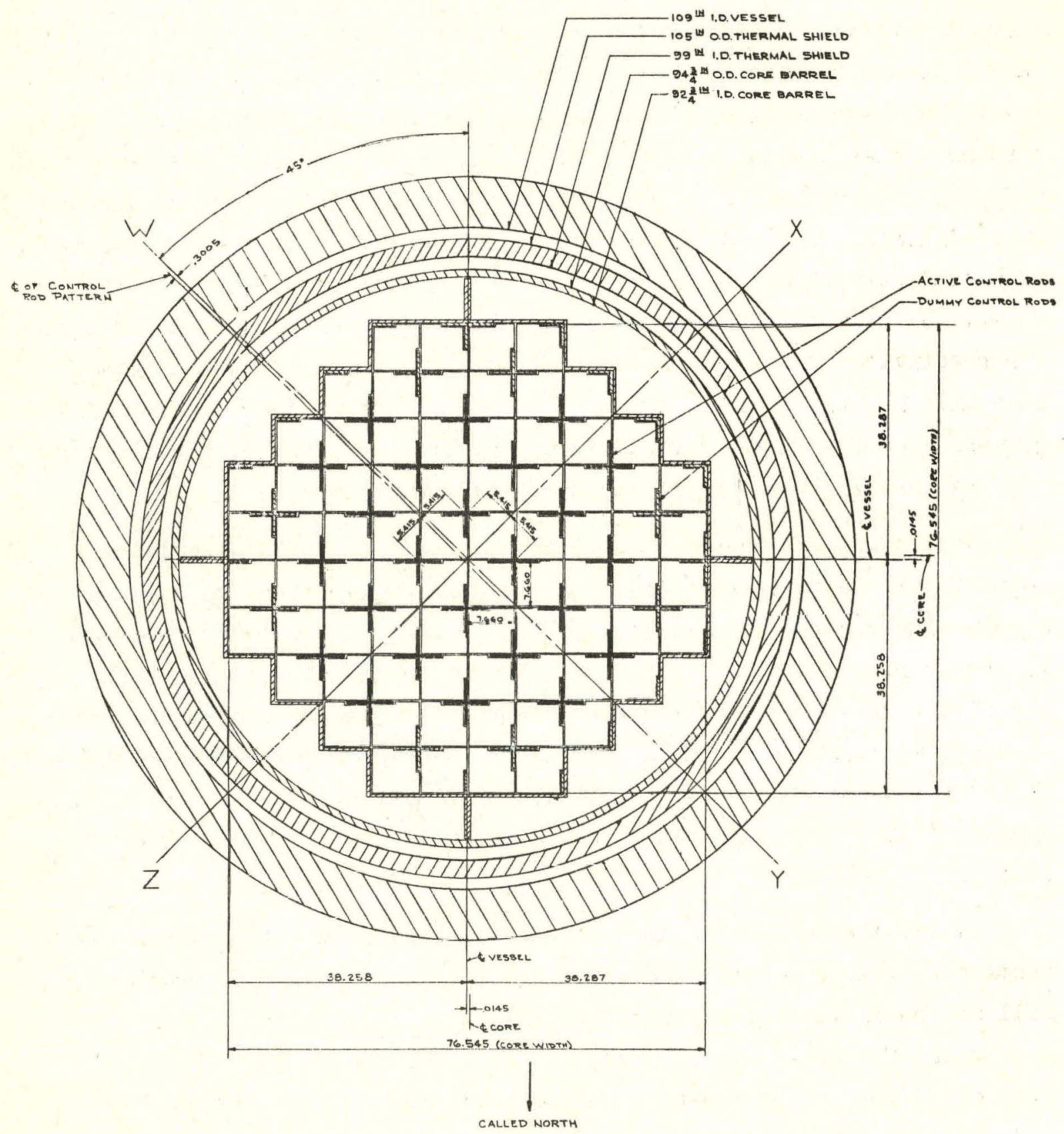

FIGURE I

YANKEE CORE CROSS SECTION 


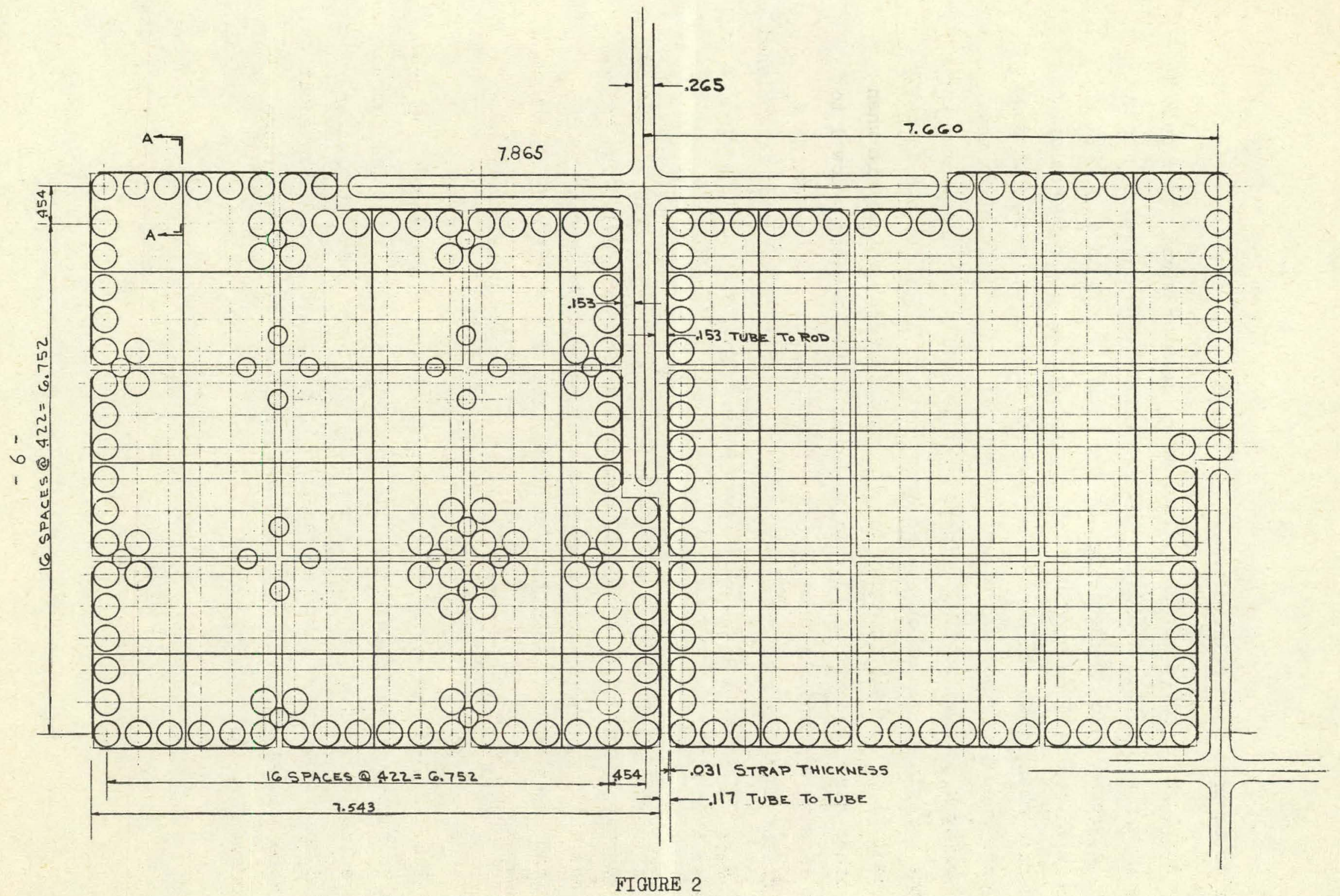

YANKEE FUEL ASSEMBLIES 
rods to be shut down cold, clean.

Although an advanced pressurized water reactor might use a soluble poison shim control to avoid the power perturbations caused by control rods, a ground rule of the design of the Yankee first core is that no soluble poison will be required for control during power operation. This rule means that the control rods alone must be able to shut down the core when it is hot and clean. Nor is it simply sufficient that they bring $k$ eff down to 1.00 . There must be sufficient additional worth in the rods to allow for one to be stuck out, to allow for a cold water accident (i.e. coolant from one loop at room temperature cuts in when the other three are at $516^{\circ} \mathrm{F}$ ), and to bring $\mathrm{k}$ sufficiently below 1 to give rise to a short negative period. Three percent is felt to be a sufficient shutdown requirement so that a ground rule has been established that $k_{\text {eff }}$ of the hot, clean first core with 24 control rods inserted be no greater than 0.97 .

Table $I$ is a reactivity listing calculater hackward from the uurned out reactor at end of life (10,000 hours at 392 thermal MW). The calculations yielding these numbers were made using methods matched to the critical experiments. As discussed above, the $24_{+}$control rods must have sul'ficient worth to bring the $\mathrm{k}$ of case 4 of Table 1 at least to $\mathrm{k}_{\text {eff }}=$ 0.97 .

Table 2 is a summary of the nuclear constants of the core which are used in subsequent calculations. The constants in this table are for an homogenized core; i.e., the fuel, zircaloy followers, and extra water around the control rod slots are assumed to be spread evenly throughout the core volume (after the application of suitable flux disadvantage factors). 


\section{TABLE 1}

\section{Reactivity Requirements of the First Yankee Core}

Core Condition $\quad \mathrm{k}_{\text {eff }}{ }^{*^{+}} \quad$ Remarks

\section{Hot, end of life, full power, equilibrium $\mathrm{Xe}$ and $\mathrm{Sm}$. \\ 2. Hot, beginning of life, full power, equilibrium $\mathrm{Xe}$ and $\mathrm{Sm}$.}

3. Hot, clean, full power.

4. Hot, clean, no power
1.1013

1.1264

1.0000

1.0691

1264
5. Cold, clean
1.1980.

Life was 10,000 hours at 392 thermal MW.

Differs from above because of stable fission products and fuel transmutation.

Differs from above because of $\mathrm{Xe}-135$ and $\mathrm{Sm}-149$ poisoning.

Differs from above because of fuel coefficient of reactivity acting on fuel temperature rise when power is drawn. Also there is a loss in $k$ due to the nonuniformity of the coolant temperature when power is drawn.

Differs from above because of the moderator and fuel temperature coefficients of reactivity.
$*$

This value of $k_{\text {eff }}$ is indicative of how much of a change in $v$ would be necessary to achieve criticality if all control were absent.

+ The number of significant digits in the figures in this and other tables should not be taken to represent the precision of the results, but rather represents the number of digits resulting from the calculation method. 
TABLE 2

Neutron Constants of the First Yankee Core

Cold

$\left(68^{\circ} \mathrm{F}\right)$
Hot, Clean,

No Power

$\left(516^{\circ} \mathrm{F}\right)$

Fast Group Constants

Age, $\tau, \mathrm{cm}^{2}$

Diffusion Coefficient, $D_{f}, \mathrm{~cm}$

Absorption Cross Section, $\Sigma_{a f}, \mathrm{~cm}^{-1}$

Fission Yield Cross Section, $\nu \Sigma_{f f}, \mathrm{~cm}^{-1}$

Removal Cross Section, $\Sigma_{r}, \mathrm{~cm}^{-1}$.

Inverse Slowing Down Length, $x_{f}, \mathrm{~cm}^{-1}$

$$
\Sigma_{\text {af }}+\Sigma_{r}=D_{f} / \tau
$$

Thermal Group Constants

Diffusion Area, $\mathrm{L}^{2}, \mathrm{~cm}^{2}$

2.5946

0.31927

0.12153

0.18057

0.6208

Inverse Diffusion Length, $x_{s}, \mathrm{~cm}^{-1}$

Mi.scellaneous Constants

Geometric Buckling, $\mathrm{B}^{2}, \mathrm{~cm}^{-2 *}$

Diffusion Coefficient, $D_{s}, \mathrm{~cm}$

Absorption Cross Section, $\Sigma_{2}, \mathrm{~cm}^{-1}$

Fission Yield Cross Section, $\nu \Sigma_{f}, \mathrm{~cm}^{-1}$
37.73

i. 1342

0.011619

0.009556

0.018441

0.1628

0.03006
0.02475

\subsection{3}

.1 .2529

0.011592

0.009768

0.013154

0.1405

4.2608

0.41525

$0.00 \% 6 \circ 25$

0.14469

0.4844 
III. THEORY OF CONTROL CALCUIA TIONS

Reactor nuclear design calculations are normally burdened by the necessity of making a large number of simplifying assumptions. Yankee, for example, has 23,142 fuel rods: within each of these there are strong variations in the neutron flux both with respect to its energy and position within the rod. It would be very difficult to have an: explicit representation of each rod. Instead, one calculates a single.. unit cell and then homogenizes its properties over the entire fuel region. The next order of geometric complexity is introduced by the 76 : assemblies and 32 slots, containing extra water and either control rods or followers. If calculations are to be performed by hand, or using one-dimensional machine codes, even this degree of heterogeneity must. be suppressed. However, it is possible with present techniques to represent this much detail in two-dimensional machine calculations. (using the PDQ codell). The completely homogenized calculations can yield reasonably reliable results for the total worth of all control rods and for over-all power sharing between regions with uniform distributions of control rods or followers. The two-dimensional techniques must be used to answer questions such as; "What happens when one control rod sticks out?", or: "What is the power distribution around a control. rod follower?".

Another field in which simplification is required is that of geometric shape. The hand calculations and one-dimensional machine codes are restricted to cylinders, spheres, or slabs. The core outer boundary must be approximated as a cylinder while the absorption per unit area of control rod is calculated from a simple slab model*. Again, the two-dimensional model is a considerable improvement but even here one cannot represent such fine points as the rounded tips of the control blades (see Figure 2).

*

Actually, this is not as bad as it seems because the extra absorption at the tips of a cruciform tends to cancel the loss in the notches. 
Yet another problem arises which presents greater difficulties than the two discussed so far. This arises from the fact that the neutrons obey the integro-differential Boltzmann equation which determines their distribution in velocity and position. The solution of this equation in even the most simplified situation is extremely cumbersome. In practice one simplifies drastically the energy distribution by assigning the neutrons to four or even two energy groups. Two group theory is used in this report. The constants for these groups are assumed to be independent of position within a region; i.e., we have postulated separability of the space and energy variables. In addition, the spatial distribution is assumed to follow the second order differential diffusion equation which amounts to a severe restriction in the complexity allowed in neutron angular distributions. This computational model can be made effective by" certain modifications. For example, in the thermal group around and in a control rod where diffusion theory is especially bad, one represents the control rod as black (completely absorbing) and applies a transport theory boundary condition to the flux and its derivative at the surface of the rod:

$$
\frac{1}{\varnothing} \frac{\mathrm{d} \emptyset}{\mathrm{dx}}=\frac{1}{.7104 \lambda_{\mathrm{tr}}}
$$

In the fast group one fits to the experimental rod worths by using diffusion theory throughout and assigning an empirical macroscopic cross section to the rod material, $\Sigma_{f C R^{*}}$ Both one and two-dimensional calculations suffer from these disadvantages, but a properly fitted $\Sigma_{f C R}$ can. generally be depended upon to give reasonably accurate worth calculations.

The remainder of this section is divided into three parts dealing with:

$$
\begin{aligned}
& \text { A. One-Dimensional Calculations, } \\
& \text { B. Two-Dimensional Calculations, } \\
& \text { and Prediction of } \Sigma_{\mathrm{fCR}}
\end{aligned}
$$




\section{A. One-Dimensional Calculations}

Here a scheme is used which is called the super cell method 12 . It starts with a calculation of the current into the control rod surface and converts this into an equivalent poison cross section homogenized over the surrounding fuel. In other words, a boundary leakage is converted to a homogeneous poison via a neutron balance. In the inner regions of Yankee, the super cell has an area of. two fuel assemblies. In calculations with 24 control rods an inner region of area equal to 48 assemblies will contain the homogenized poison while the remaining area, corresponding to 28 assemblies, will be free of poison.

Figure 3 shows one fourth of the control rod super cell and its one-dimensional representation: In this one-dimensional cell, the thermal flux obeys the boundary condition of equation $I$ at $x=b$ and has zero derivative at $x=m$. The group constants for the core regions will be those of Table 2, while the control rod has $D_{f}=1, \Sigma_{r}=0$, and an absorption cross section in the fast group equal to $\Sigma_{f C R}$. Setting $D_{f}=I$ and $\Sigma_{r}=0$ are approximations close to the truth: the results are very insensitive to actual values used.

In the thermal group, we assume a unit source so that the diffusion equation becomes (the subscript 2 stands for region 2, the core: I would be the rod itself):

$$
\text { ( Ds } \left.\frac{d^{2}}{d x^{2}}-\Sigma_{a}\right) \phi_{2 s}+1=0
$$

The solution which satisfies the boundary conditions yields a current per unit area into the rod surface as follows:

$$
Q_{s}=\left.D_{s} \frac{d \emptyset}{d x}\right|_{b} \quad=\frac{1}{2.13 \Sigma_{a}-x_{s} \frac{Y\left(x_{s} b\right)}{Z\left(x_{s} b\right)}}
$$




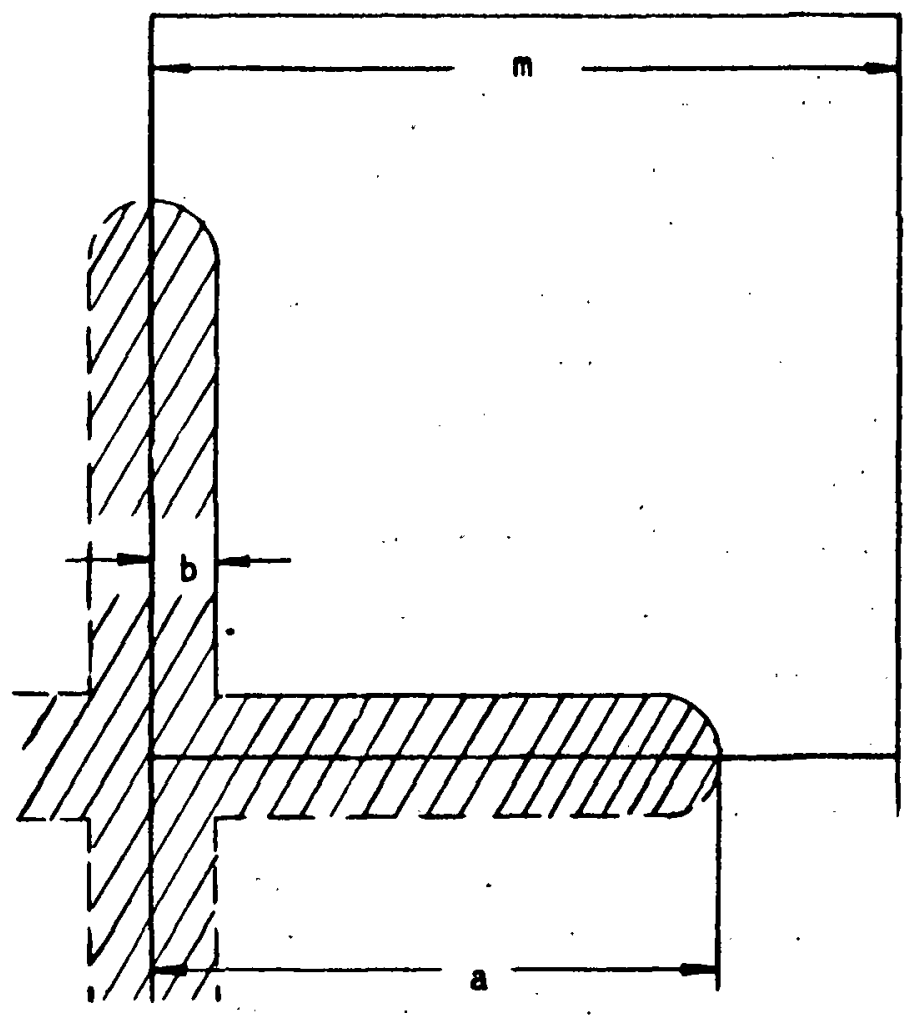

it th OF CONTROL SUPER CELL
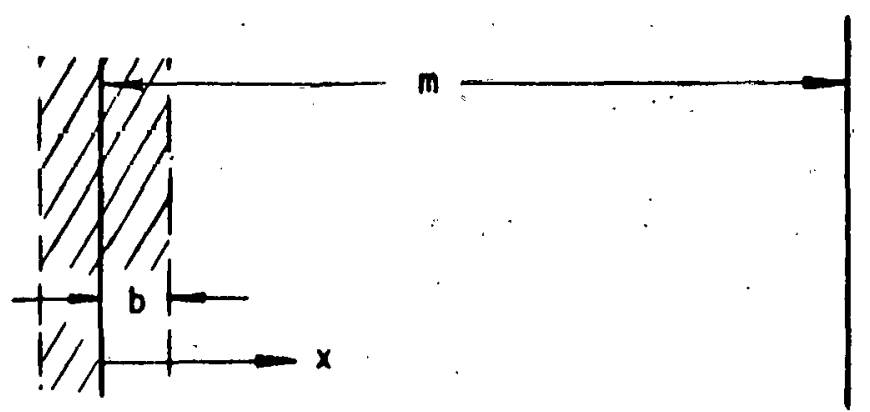

ONE DIMENSIOHAL REPRESENTATION

FIGURE 3 - IDEALIZATIONS OF CONTROL ROD SUPER-CELL 


$$
\begin{aligned}
\frac{Y\left(x_{s} b\right)}{Z\left(x_{s} b\right)} & =\frac{\cosh x_{s} b-\left(\sinh x_{s} b\right)\left(\tanh x_{s} m\right)}{\sinh x_{s} b-\left(\cosh x_{s} b\right)\left(\tanh x_{s} m\right)} \\
& \cong-1
\end{aligned}
$$

In the fast group there are fluxes in each region which satisfy the following equations and boundary conditions: (There is a unit source in the moderator region 2.)

$$
\begin{aligned}
& \left(\frac{d^{2}}{d x^{2}}-\Sigma_{f C R}\right) \emptyset_{l f}=0 ;\left.\frac{d \phi_{1 f}}{d x}\right|_{0}=0 \\
& \left(D_{f} \frac{d^{2}}{d x^{2}}-\frac{D_{f}}{\tau}\right) \dot{\emptyset}_{2 f}+1=0 ;\left.\quad \frac{d \phi_{2 f}}{d x}\right|_{m}=0 \\
& \emptyset_{1 f}(b)=\emptyset_{2 f}(b) ;\left.\quad \frac{d \emptyset_{1 f}}{d x}\right|_{b}=\left.D_{f} \frac{d \phi_{2 f}}{d x}\right|_{b}
\end{aligned}
$$

The fast absorption in the rod is obtained by integrating the product $\emptyset_{\text {lf }} \Sigma_{f C R}$ over region 1 . This yields an absorption per unit surface, equivalent to equation 3 , as follows:

$$
\begin{aligned}
Q_{f}=\int_{0}^{b} \phi_{I f} \Sigma_{f C R} d x= & \frac{1}{\left[\frac{D_{f}}{\tau b \Sigma_{f C K}}-x_{f} \frac{Y\left(x_{f} b\right)}{Z\left(x_{f} b\right)}\right]} \\
& \frac{Y\left(x_{f} b\right)}{Z\left(x_{f} b\right)} \approx-\operatorname{coth} x_{f}^{m}
\end{aligned}
$$

The $Q_{f}$ and $Q_{s}$ values are then converted into equivalent area absorption cross sections by using the relation:

$$
\frac{\text { control rod absorption }}{\text { total absorption }}=\frac{\text { rod perimeter } x \cdot Q}{\text { total source }}
$$


Let $\Sigma_{a C R}$ and $\Sigma_{a f C R}$ be the thermal and fast group homogenized poison cross sections of the rods. They are used in subsequent one-dimensional calculations by adding them to regions which contain control.rods. From equation 7 they can be shown to be:

$$
\begin{aligned}
& \frac{\Sigma_{a C R}}{\Sigma_{a}}=\frac{1}{\left(\frac{m^{2}-2 a b+b^{2}}{2 a}\right)\left(2.13 \Sigma_{a}+x_{s}\right)-1} \\
& \frac{\Sigma_{a f C R}}{D_{f} / \tau}=\frac{1}{\left(\frac{m^{2}-2 a b+b^{2}}{2 a}\right)\left(\frac{D_{f}}{\tau b \Sigma_{f C R}}+x_{f} \operatorname{coth} x_{f} m-1\right.}
\end{aligned}
$$

One problem which arises in this scheme comes from the assumption of uniform sources of neutrons. In actual fact, these sources dip near the rod because of the absorption by the rod; Thus, constant sourocs will tend to overestimate absorption by the rod. If the total. rod worth is to be held to the correct value, then a smaller value of $\Sigma_{\text {fr.R }}$ must be used than in a morc explicit two-dimensional calculation.

If a core (unlike Yankee which has its rods grouped towards the center) is uniformly rodded; then one can derive a hand calculation formula for the effect of the poison cross sections (equations 8 and 9) on the neutron economy. It is of interest to derive this formula as it will be of use in the analysis of the experimental data to be described in section IV. We start with the two group neutron diffusion equations.

$$
\begin{aligned}
& \left(D_{f} \nabla^{2}-\Sigma_{a f}-\Sigma_{r}\right) \phi_{f}+\frac{\nu \Sigma_{f f} \phi_{f}+\nu \Sigma_{f s} \phi_{s}}{k}={ }^{\prime}=0 \\
& \left(D_{s} \nabla^{2} \cdots \Sigma_{a}\right) \emptyset_{s}+\Sigma_{r} \emptyset_{f} \quad=0 \\
& -18-
\end{aligned}
$$


$k$. is the value of criticality required to make these equations balance. If one assumes an equivalent bare core, then $\nabla^{2} \emptyset^{\prime}=-B^{2} \varnothing$ ( $B^{2}$ is obtained from the actual dimensions plus reflector savings), and 10 and 11 become:

$$
\begin{aligned}
& -\left(D_{f} B^{2}+\Sigma_{a f}+\Sigma_{r}-\frac{\nu \Sigma_{f f}}{k}\right) \emptyset_{f}+\frac{\nu \Sigma_{f s}}{k} \emptyset_{s}=0 \\
& -\left(D_{s} B^{2}+\Sigma_{a}\right) \emptyset_{s}+\Sigma_{r} \emptyset_{f}
\end{aligned}
$$

If these simultaneous, linear, homogeneous equations in $\varnothing_{\mathrm{s}}$ and $\emptyset_{f}$ are to have a solution, then the determinant of the coefficients must vanish, which yields an expression for $k$ :

$$
k=\frac{\nu \Sigma_{f f}+\frac{\nu \Sigma_{f} \Sigma_{r}}{D_{s} B^{2}+\Sigma_{a}}}{D_{f} B^{2}+\Sigma_{a f}+\Sigma_{r}}
$$

If one now adds to the core uniform thermal and fast control rod poisons (equations 8 and 9), we can easily calculate their effect on $k$ from equation 14. The result is:

$$
\begin{aligned}
k_{\text {rodded }} & =k_{\text {unrodded }} R \\
R & =R_{s} R_{f} \\
R_{s}= & \nu \Sigma_{f f}+\frac{\nu \Sigma_{f} \Sigma_{r}}{D_{s} B^{2}+\Sigma_{a}+\Sigma_{a C R}}=\frac{I+L^{2} B^{2} \cdot}{I+L^{2} B^{2}+\frac{\Sigma_{a C R}}{\Sigma_{a}}}\left[\frac{\Sigma_{f f}\left(I+L^{2} B^{2}+\frac{\Sigma_{a C R}}{\Sigma_{a}}\right)+\eta f}{\nu \Sigma_{r f}}\right]
\end{aligned}
$$




$$
R_{f}=\frac{D_{f} B^{2}+\Sigma_{a}+\Sigma_{r}}{D_{f} B^{2}+\Sigma_{a}+\Sigma_{r}+\Sigma_{a f C R}}=\frac{1+\tau B^{2}}{1+\tau B^{2}+\frac{\Sigma_{a f C R}}{D_{f} / \tau}}
$$

$R$ is a control reduction factor, defined as the ratio of $k$ with control to the value it would have wi thout control. $I / R$ is the maximum controliable $k$; i.e., an unrodded $k$ of $1 / R$ would be brought to 1.00 by insertion of control.

B. Two-Dimensional Calculations

There is actually very little to discuss here; one sets up the geometry of the core explicitly, at least insofar as to represent con- $t^{*}$ trol rods, followers, associated extra water, and fuel assemblies. The $\cdots$ PDQ code allows one to apply the boundary condition of equation 1 at the surface of the rod in the thermal group. In the fast group $\Sigma_{f C R}$ is used in the control rod itself, along with $D_{f}=1$ and $\Sigma_{r}=0$. The PDQ can then be used to find $k_{\text {eff }}$ for any desired combination of control rods fully inserted. Partial insertion willlıs are more difficult to calculate. One can use so-called flux synthesis techniques $/ 3$ to fit together PDQ's.. run for planes through the reactor at different heights, but this is fairly cumbersome and not always as accurate as may be desired. The three dimensional codes do not yet have provision for enough mesh points to accurately portray the Yankee reactor.

\section{Prediction of $\Sigma_{f C R}$}

Since the resonance structure of the silver, cadmium, and indium used in the Yankee control rods is fairly well known 4 , it should be possible to calculate $\Sigma_{f C R}$, the empirical fast neutron absorption cross section, from the basic cross section data. This section shows how this is done, and the results appear to agree reasonably with values obtained from other methods used. However, it has been decided to let the primary source of these numbers be empirical so that $\Sigma_{f C R}$ can be a catch-all which compensates for all inaccuracies and short-comings of 
the theoretical model used over a small range about the experiments to which it is fit. If the empirical value of $\Sigma_{f C R}$ agrees with the calculated value, then one has greater confidence in the method.

The method used to find $\Sigma_{f C R}$ employs what is called "blackness theory", and is similar to that used by S. Stein in his calculation of resonance escape probability $\frac{15}{}$. We start by calculating $\alpha(E)$, the ratio of current to flux at energy $E$ at the surface of a control slab surrounded by core. (See Appendix 1 for a derivation of this formula.)

$$
\alpha(E)=\frac{1-2 E_{3}\left(2 b \Sigma_{a}\right)}{2+6 E_{4}\left(2 b \Sigma_{a}\right)}
$$

In equation $18, E_{3}$ and $E_{4}$ are Plazek functions $16,2 \mathrm{~b}$ is the thickness of the control rod in $\mathrm{cm}$, and $\Sigma_{a}$ is the absorption cross section of the control rod for neutrons of energy $\mathrm{E}$.

Figures 4, 5, and 6 are plots of $\alpha$ versus $E$ for $\mathrm{Ag}-\mathrm{In}-\mathrm{Cd}$ $(80-15-5), A g-C d(70-30)$, and boron-10 stainless steel slabs. $285^{\prime \prime}$ in thickness. These were constructed by simply using equation 18 and BNL-325 cross section data 14 . Saturation at $\alpha=0.5$ simply indicates that the rod is black at that energy.

The next step is to obtain an effective $\bar{\alpha}$ for the entire fast neutron group. The curves of figures 4, 5, and 6 were integrated, thus yielding the integral of $\alpha \mathrm{dE} / E$ from $0.625 \mathrm{ev}$ to $5530 \mathrm{ev}$. An $\bar{\alpha}$ for group three of three fast groups is then:

$$
\bar{\alpha}_{3}=\frac{1}{\ln \frac{5530}{.625}} \int_{.625}^{5530} \alpha(E) \frac{d E}{E}
$$

If $\alpha$ is assumed to be zero for energies higher than $5530 \mathrm{ev}$ (groups 1 and 2), the MUFT 4 fast neutron spectrum code $/ 7$ can be used to tell us how to obtain $\bar{\alpha}$ for a single fast group. These values are displayed in

* An average flux is obtained for each of the fast groups, which is then used to weight the $\bar{\alpha}_{3}$ to get $\bar{\alpha}$. 


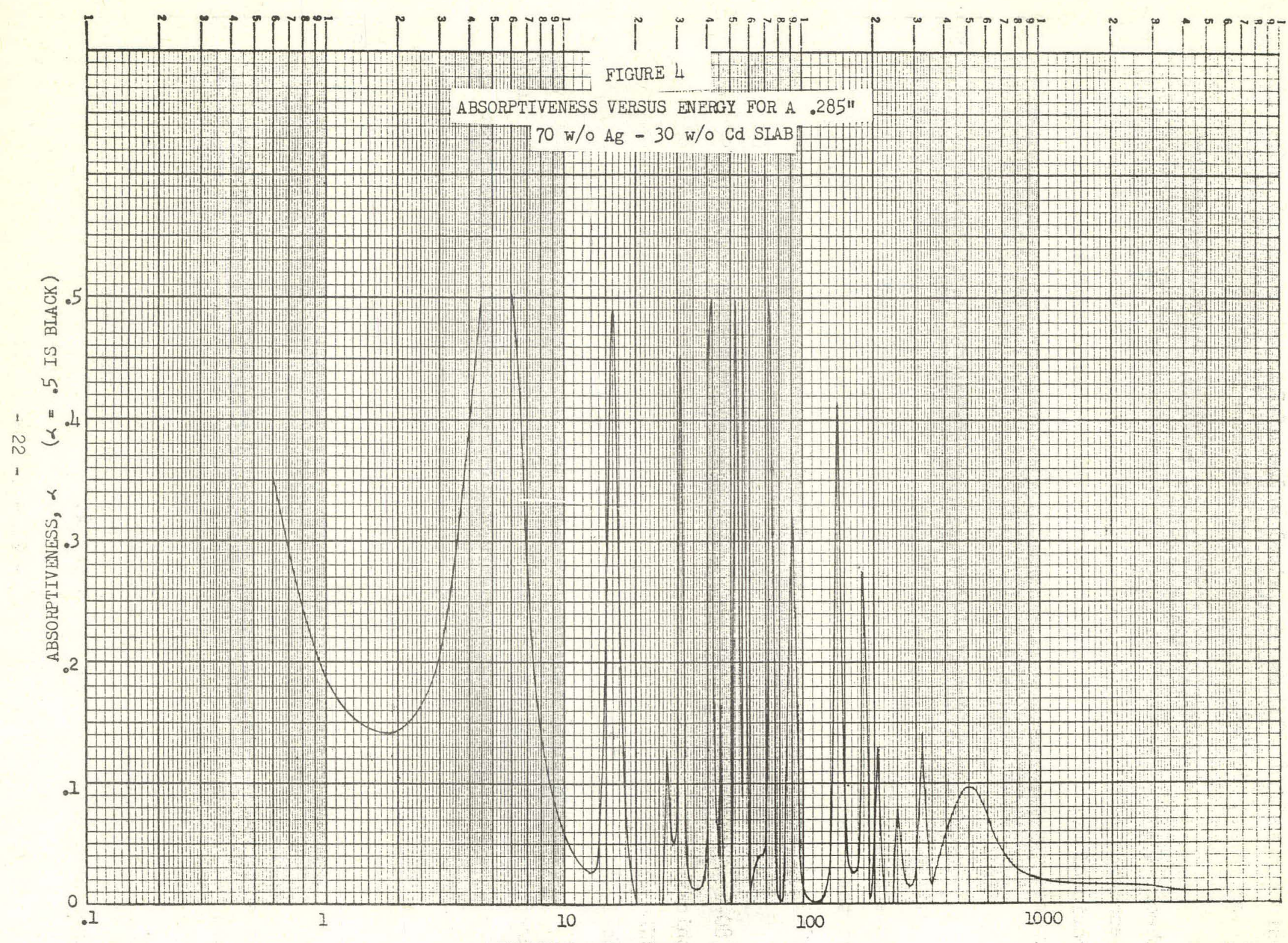

ENERGY E, ELECTRON YOLTS 


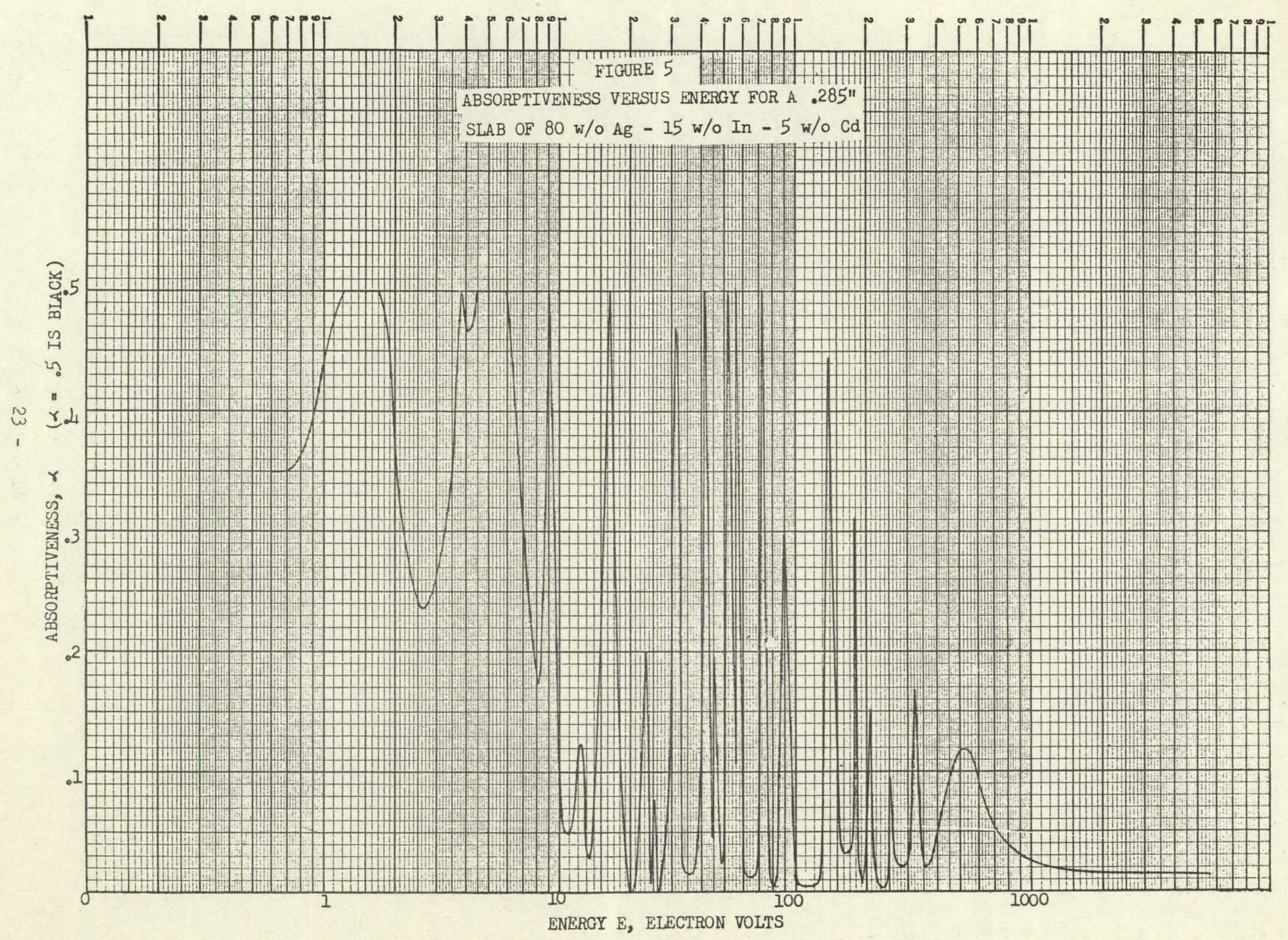




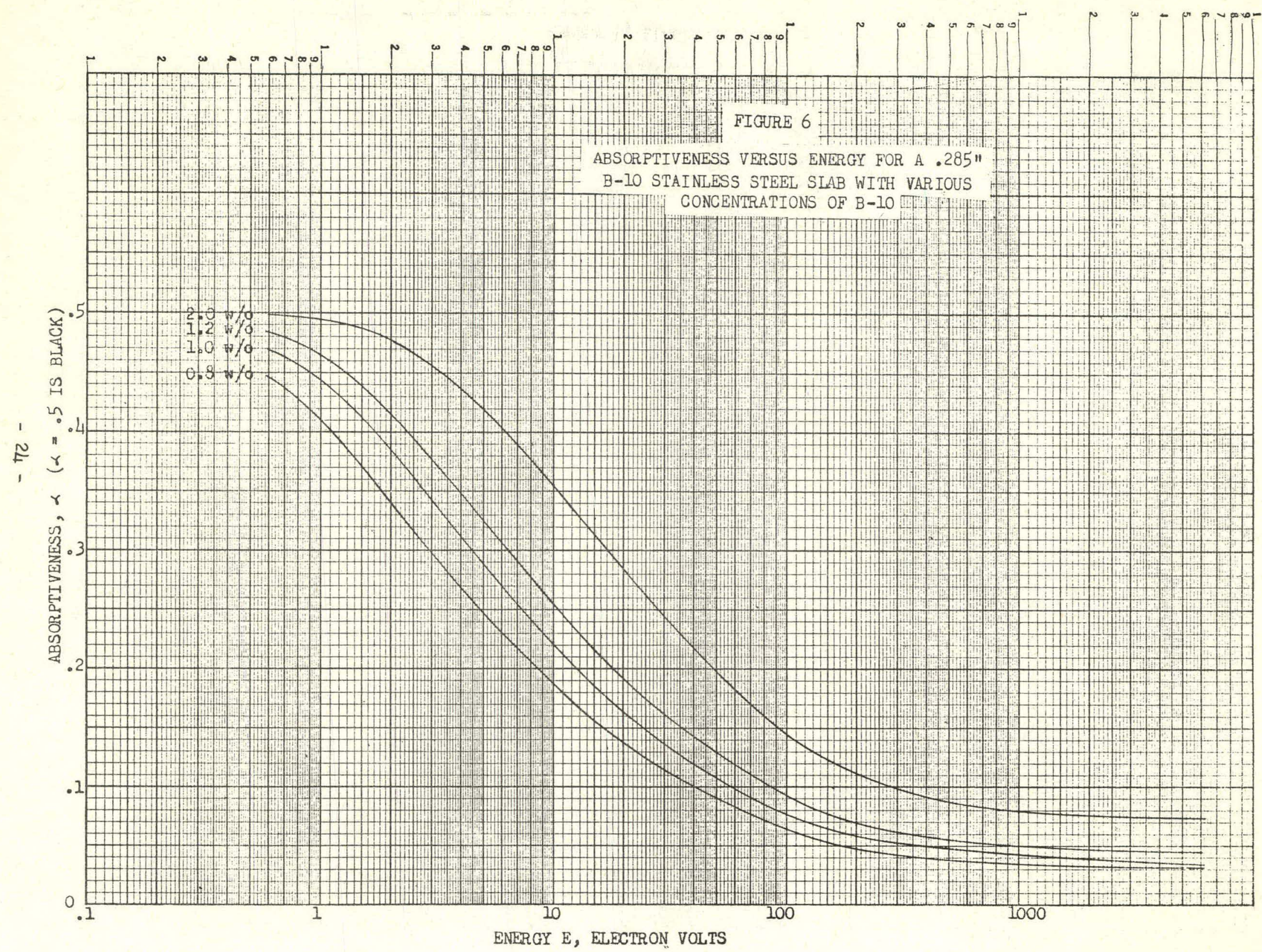


Table 3. $\Sigma_{f C R}$ is next obtained from the formula given below; which is derived in Appendix 2.

$$
\bar{\alpha}=\sqrt{\Sigma_{f C R}} \tanh \left(b \sqrt{\Sigma_{f C R}}\right)
$$

The results are shown in Table 3.

TABLE 3

Calculated Values of $\bar{\alpha}$ and $\Sigma_{f C R}$ .285 inch Slabs

$\begin{array}{lllc}\text { Material } & \bar{\alpha}_{3} & \bar{\alpha} & \Sigma_{\text {fCR }}, \mathrm{cm}^{-1} \\ 70 \% \mathrm{Ag}-30 \% \mathrm{Cd} & .125 & .0417 & .116 \\ 80 \% \mathrm{Ag}-15 \% \mathrm{In}-5 \% \mathrm{Cd} & .179 & .0600 & .167 \\ \text { Steel, 0.8 w/o B-10 } & .125 & .0417 & .116 \\ \text { Steel, 1.0 w/0 B-10 } & .144 & .0480 & .134 \\ \text { Steel, 1.2 w/0 B-10 } & .161 & .0537 & .150 \\ \text { Steel, 2.0 w/O B-10 } & .209 & .0697 & .194\end{array}$

It is interesting to note that in Table 3 a boron-10 loaded stainless steel rod can easily be as effective as the silver alloys. A $1.2 \mathrm{w} / \mathrm{O}$ B-10 rod is probably at the limit of present metallurgical techniques; it is seen to be almost as good as the Ag-In-Cd rod. Some confirmation of the values for $\Sigma_{f C R}$ can be found in the work of Neuhold at Bettis $/ 8$. He gives a $\Sigma_{f C R}$ of $.13 \pm .01$ for the Ag-Cd rod. For a hafnium rod, supposed to have about the same worth as Ag-In-Cd, he gives $\Sigma_{f C R}=.169 \pm .015$. These compare to our calculated values of 0.116 and 0.167 , respectively. 


\section{EXPERIMENTAL INFORMATION}

The Yankee critical experiments have been described fully in YAEC-94. It is the purpose of this section to describe the calculations performed on this data, with the general purpose of leading to an experimental value of $\Sigma_{\mathrm{fCR}}$. The critical experiments were performed in a part-size mockup of the full Yankee core, shown from the top in Figure 7. The nine control rods were of a 70\% Ag - 30\% Cd alloy, with a span of 7.812 inches and a blade thickness of .285 inches. The information of most interest was obtained by two types of experiments: measurement of the negative axial buckling in a region containing a bank of control rods; and measurements by boron substitution of the worths of individual rods, banks inserted to various depths, and groups of rods.

A. Negative Buckling Measurements

Figure 8 is a typical axial flux traverse taken in a core which has all nine control rods inserted in a bank to a depth of $81.3 \mathrm{~cm}$ from the top of the core. In the rodded part of the core, the flux falls on an exponential, whose slope on the semilog plot yields tho negalive axial buckling" 'l'he sum of this and the positive radial buckling is the material buckling of the rodded region, $B_{\text {rodded }}^{2}$ In conjunction with the already known (from the clean critical data) value of the $B^{2}$ of the unrodded core we can calculate $R$, the control reduction factor (see Section III A):

$$
R=\frac{k\left(B_{c l e a n}^{2}\right)}{k\left(B_{\text {rodded }}^{2}\right)}
$$

Table 4 is a summary of the negative $B^{2}$. results obtained in the three critical experiment cores. They were obtained from plots like Figure 8, and the use of equation 21. The $k$ formula used in 21 is one which includes the effect of epithermal fissions in $U^{235}$, and is to be described in a forthcoming YAEC report on the analysis of the Yankee critical experiments. 


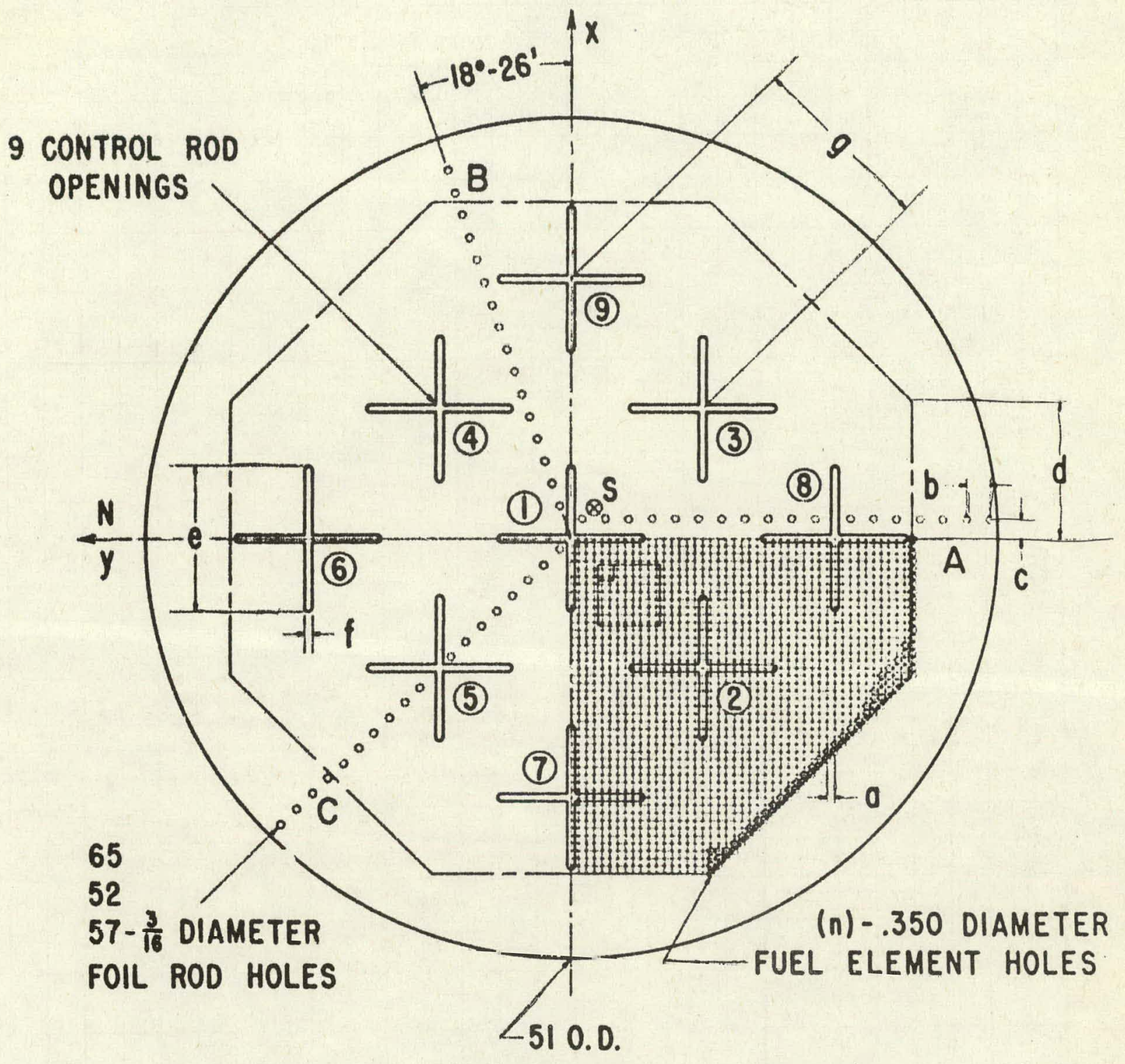

\begin{tabular}{|c|c|c|c|c|c|c|c|c|}
\hline$W: M$ & a & b & C & d & e & $f$ & g & $n$ \\
\hline $2.2: 1$ & 0.405 & 0.810 & 1.013 & 7.290 & 8.470 & 0.370 & 10.310 & 6164 \\
\hline 2.9 & 0.435 & 0.870 & 1.088 & 7.830 & 8.200 & 0.370 & 10.458 & 6184 \\
\hline $3.9: 1$ & 0.470 & 0.940 & 1.175 & 8.460 & 7.990 & 0.370 & 10.635 & 6220 \\
\hline
\end{tabular}

FIGURE 7

TOP VIEW OF YANKEE CRITICAL EXPERIMENTS 


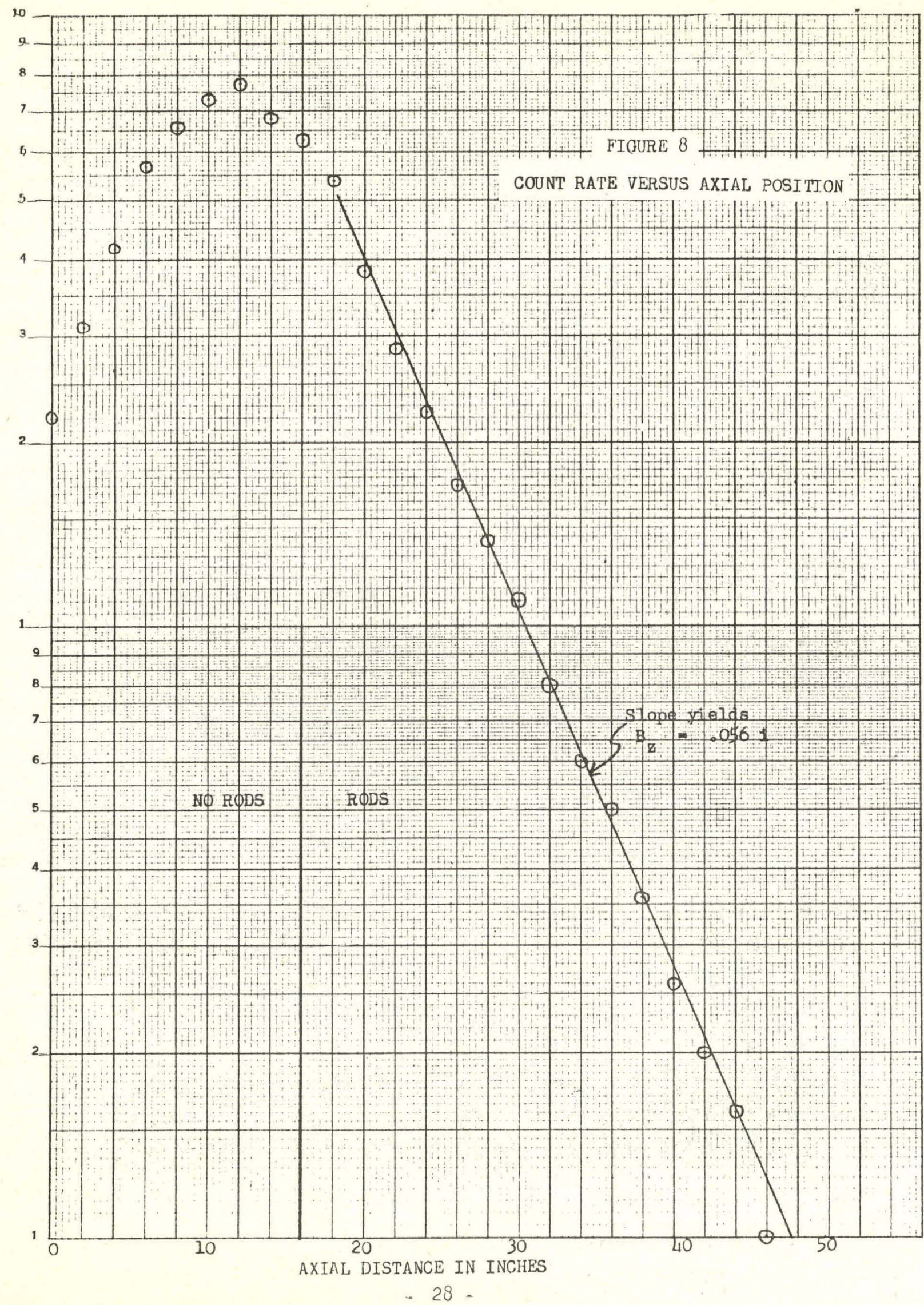




\section{TABLE L}

Negative $B^{2}$ Analysis of Yankee Critical

Experiment Control Rod Worths

\begin{tabular}{|c|c|c|c|c|c|c|}
\hline Core & Run Number & $\mathrm{cm}^{-2} \times 10^{-4}$ & $\begin{array}{c}\mathrm{B}_{\text {rodded }}^{2} \\
\mathrm{~cm}^{-2} \times 10^{-4} \\
\end{array}$ & $\begin{array}{c}\mathrm{B}_{\text {clean }}^{2} \\
\mathrm{~cm}^{-2} \times 10^{-4} \\
\end{array}$ & $\mathrm{R}$ & $I / R$ \\
\hline $2.2 / 1$ & 49 & 31.0 & -7.55 & 40.1 & .801 & 1.248 \\
\hline $2.9 / 1$ & 88 & 24.9 & 4.77 & 52.5 & .816 & 1.226 \\
\hline $2.9 / 1$ & 89 & 21.8 & 6.74 & 52.5 & .830 & 1.205 \\
\hline $2.9 / 1$ & .90 & 22.5 & 5.26 & 52.5 & .825 & 1.213 \\
\hline $2.9 / 1$ & 96 & 41.3 & 1.46 & 52.5 & .811 & 1.233 \\
\hline $2.9 / 1$ & 166 & 33.2 & 3.13 & 52.5 & .817 & 1.224 \\
\hline $2.9 / 1$ & 168 & 26.8 & 0.01 & 52.5 & .806 & 1.241 \\
\hline
\end{tabular}

Average $\mathrm{R}$ for $2.9 / 1$ core $=.817$; 


\section{B. Boron Substitution Measurements}

In this type of measurement, the boron concentration required for criticality is measured with and without the particular combination of rods whose worth is to be measured. One then calculated $R$ by taking the ratios of the $\mathrm{k}^{\mathrm{i}} \mathrm{s}$ calculated for the two boron concentrations,

$$
R=\frac{k \text { (boron concentration w/o rods) }}{k \cdot(\text { boron concentration with rods })}
$$

These measurements have been performed in two ways. In the first of these, full insertion worths of individual rods and groups of rods have been measured, with the results shown in $\mathrm{T}$ able 5 (see the rod numbering system of Figure 7). Another group of measurements, performed in the 2.9/1 and 3.9/1 cores oniy, consisted in balancing bank insertion worth against boron concentration. Figure 9 describes this latter experiment; critical boron concentrations were obtained for several different values of $x$, the rod bank height. Table 6 presents the experimental data and its analysis as far as $R$ values.

Although this boron substitution is basically an excellent method of obtaining $R$ values, unfortunately there was not enough fuel available to allow a measurement of $\ddot{R}$ for a fully rodded core in any of the three critical experiments. For example, the fully rodded core measurements would have cores with clean $\mathrm{k}^{\prime} \mathrm{s}$ of at least 1.2 ( see $\mathrm{T}$ able 4), while the maximum clean $\mathrm{k}$ actually obtainable was about 1.14. This means that various calculational models will have to be used to extrapolate the data of Tables 5 and 6 to fully rodded cores. Section $C$ below outlines this extrapolation.

\footnotetext{
* Generally, a slight period correction must also be made when equation 22 is used.
} 


\section{TABLE 5}

Full Insertion Worths of Control Rods in Yankee Critical Cores

2.2/1 Core

2.9/1 Core

3.9/1 Core

4704 Fuel Rods, Radius $41.13 \mathrm{~cm}$ 4704 Fuel Rods, Radius $43.88 \mathrm{~cm}$

4468 Fuel Rods, Radius $46.03 \mathrm{~cm}$

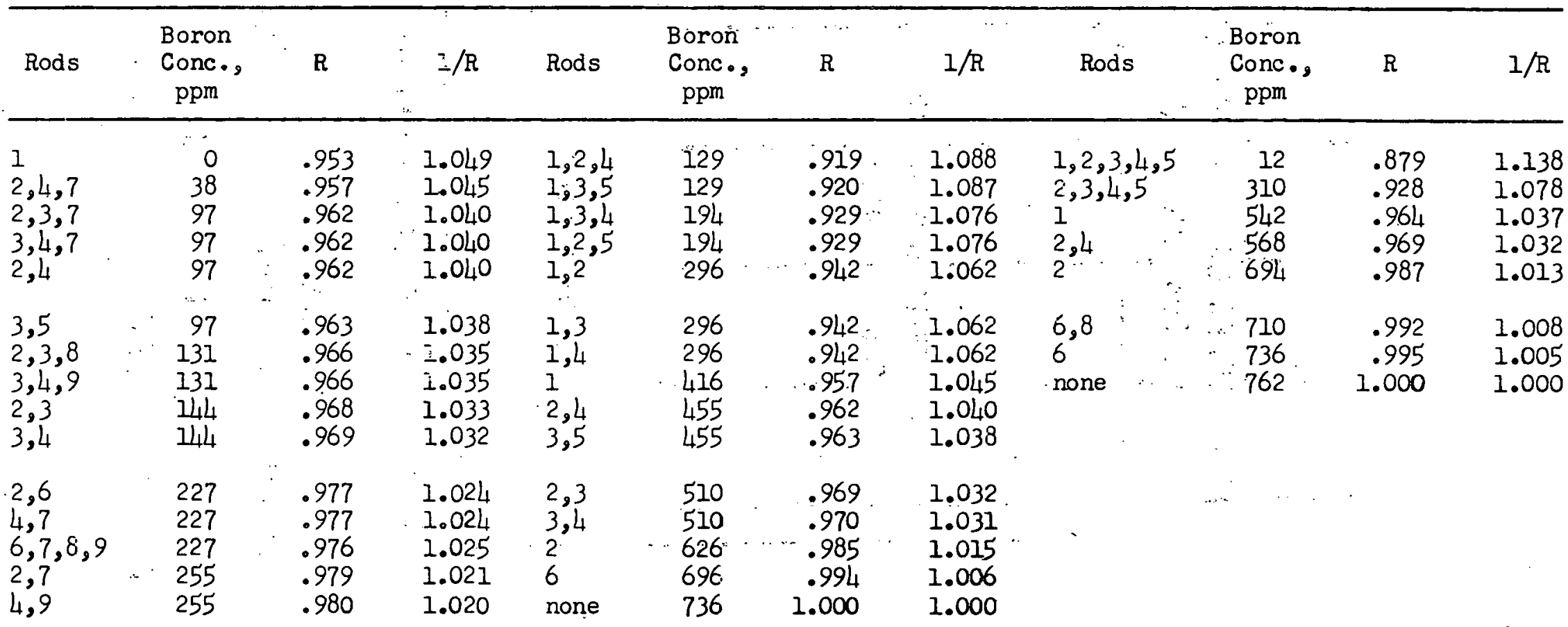

$\begin{array}{llll}2 & 283 & .982 & 1.018 \\ 7,8,9 & 283 & .982 & 1.018 \\ 7,9 & 332 & .988 & 1.012 \\ 7,8 & 332 & .988 & 1.012 \\ 6 & 399 & .996 & 1.004 \\ & & & \\ \text { none } & 439 & 1.000 & 1.000\end{array}$




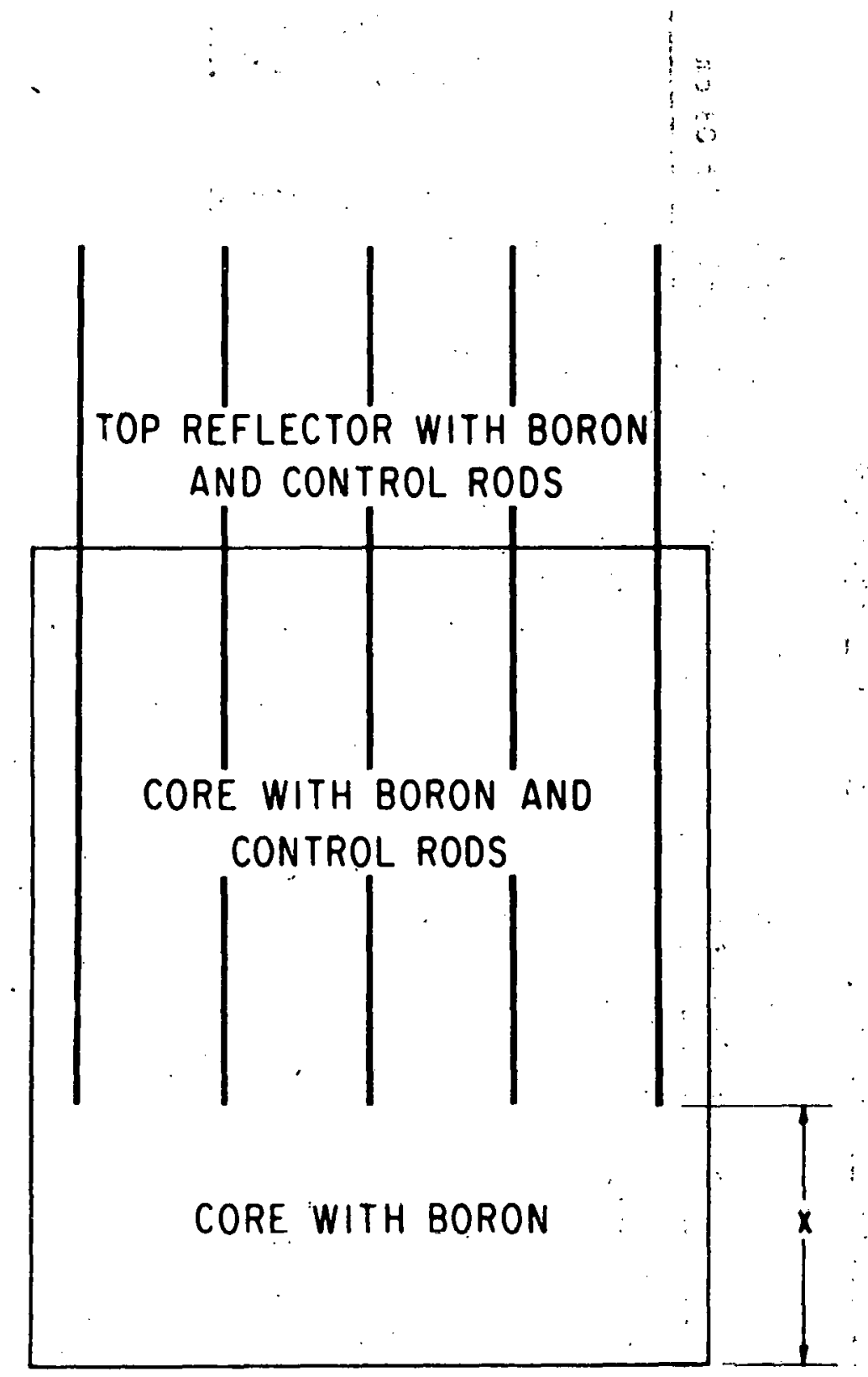

BOTTOM REFLECTOR WITH BORON

FIGURE 9.

YANKEE CRITICAL EXPERIMENT

BALANCE OF BANKED ROD POSITION

AGAINST BORON CONCENTRATION 
TABLE 6

Balance of Banked Rod Insertion Versus Boron Addition

A. 2.9/1 Core Loaded with 4704 Fuel Rods to a Radius of $43.88 \mathrm{~cm}$

$\quad \mathrm{x}, \mathrm{cm}$
Distance of Bank
from Core Bottom
Concentration

ppm
WANDA $\Sigma_{p}$

WANDA $\Sigma_{p}$
in Rodded
Region, $\mathrm{cm}^{-1}$
(30\% in fast group)

$R$ for

Bank at $x$
R Extrapolated

to Full Insertion

from $\Sigma_{p}$

\begin{tabular}{|c|c|c|c|}
\hline $\begin{array}{r}121.9 \text { (rods out) } \\
38.5 \\
41.5 \\
47.1\end{array}$ & $\begin{array}{l}736 \\
129 \\
194 \\
296\end{array}$ & $\begin{array}{l}.01786 \\
.01779 \\
.01775\end{array}$ & $\begin{array}{r}1.000 \\
.919 \\
.929 \\
.942\end{array}$ \\
\hline
\end{tabular}

B. 3.9/1 Core Loaded with 44668 Fuel Rods to a Radius of $46.03 \mathrm{~cm}$

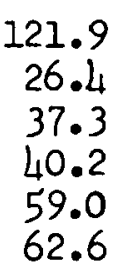

762
12.5
259
310
542
568

.01619
.01673
.01600
.01560
.01626

1.000

.879

.921

.928

.964

.969

.806

.806

.806

.807

.806

Average Values of Extrapolated R's

\begin{tabular}{|c|c|c|}
\hline Core & $\mathrm{R}$ & $1 / R$ \\
\hline $\begin{array}{l}2.9 / 1 \\
3.9 / 1\end{array}$ & $\begin{array}{r}.786 \\
.806\end{array}$ & $\begin{array}{l}1.272 \\
1.241\end{array}$ \\
\hline
\end{tabular}




\section{One-Dimensionai Calculations}

The first step in this extrapolation procedure was to run a one-dimensional diffusion theory calculation (WANDA codo $/ 9$ ) in the axial direction of Figure 9. This code has a criticality search feature, in which it will search for the poison cross section required in a single region to make the whole core critical. This was run on the data of Table 6 to give the equivalent control rod poison cross section needed to make the cores critical for each value of $x$ (the bank height). IIf these values are reasonably independent of $x$ over a fairly broad range then their average can be applied to the whole core to extrapolate to complete shütdown with all rods inserted $(x=0)$. Table 6 also shows the results of this series of calculations.

The next step in the analysis was to combine the extrapolated full insertion $R^{\prime}$ 's of Table 6 with the negative $B^{2} R^{\prime} s$ of Table 4 , and deduce a value of $\sum_{\text {fCR. }}$ from them. This was done by calculating an. $R_{s} \because$ from equations 8 and 16 , dividing this into the combined $R$ to get $R_{f}, \cdots$ and then deducing $\Sigma_{\text {fCR }}$ from equations 9 and 17. Table 7 is a sumary of thcse results. From this dața it would seem reasonable to use a value of about $.08 \mathrm{~cm}^{-1}$ for $\Sigma_{f C R}$ in one-dimensional calculations.

\section{TABLE 7}

Deduction of One-Dimensional Fast Neutron

Empirical Absorption Cross Section, $\Sigma_{f C R}$

\begin{tabular}{|c|c|c|c|}
\hline Core & Experimental R & Calculated $\mathrm{R}_{\mathrm{s}}$ & $\begin{array}{c}\text { Resulting } \\
\mathrm{cm}^{-1} \\
\end{array}$ \\
\hline $2.2 / 1$ & .801 & .879 & .074 \\
\hline $2.9 / 1$ & .801 & .879 & .079 \\
\hline $3.9 / 1$ & .806 & .876 & .075 \\
\hline
\end{tabular}


One calculational check on this one-dimensional model has been its use in a radial WANDA calculation, with rings of poison (calculated from equations 8 and 9) representing rings of control rods. This is essentially the same calculation as in the axial bank case, except that the bank is here radial. This has been done on the $3.9 / 1$ core, with the results presented in Table 8 . These results are probably as good as one can expect from a simple one-dimensional model.

\section{Two-Dimensional Calculations}

In order to check out the use of two-dimensional techniques, the PDQ code was also applied to the $3.9 / 1$ critical experiment. In the thermal group, equation 1 was applied at the surface of the rod. In the fast group $D_{f}=1.00, \Sigma_{r}=0$, and $\Sigma_{f C R}=.08$ and .12 was applied in the control rod interior. The results, shown in Table 8, clearly. favor the use of $0.12 \mathrm{~cm}^{-1}$ for $\Sigma_{f C R}$ in a two-dimensional calculation. This value agrees quite well with the analytical prediction of .116 (Table 3) and Neuhold's value of .13 \pm .01 (reference' 8 ). The reason it is higher than the value to be used in one-dimensional calculations was explained in Section III A, as being due to the dip in the source to the thermal group near the rod caused by fast absorption in the rod. The difference could be removed by using a more accurate onedimensional model, but the present model's utility lies in its simplioity so that. i.t can be used in survey calculations. Table 8 clearly demonstrates the clear superiority of two-dimensional techniques where accuracy is required. 


\section{TABLE 8}

One and Two-Dimensional Calculations of Worths of Rod Rings

\begin{tabular}{|c|c|c|c|c|c|}
\hline 1 & Rod Group & $\begin{array}{c}\text { Experimental } \mathrm{R} \\
(\mathrm{Table} 5)\end{array}$ & $\begin{array}{l}\text { One-Dimensional } \mathrm{R} \\
\Sigma_{\mathrm{fCR}}=. .08 \mathrm{~cm}^{-1}\end{array}$ & $\begin{array}{l}\text { Two-Dimensional } \mathrm{R} \\
\Sigma_{\mathrm{fCR}}=.08 \mathrm{~cm}^{-1}\end{array}$ & $\begin{array}{l}\text { Two-Dimensional } \\
\Sigma_{\mathrm{fCR}}=.12 \mathrm{~cm}^{-1}\end{array}$ \\
\hline ; & $1,2,3,4,5$ & .879 & .861 & .896 & .882 \\
\hline & $2,3,4,5$ & .928 & .902 & .931 & .924 \\
\hline & 1 & .964 & .961 & .970 & .967 \\
\hline
\end{tabular}


V. CALCULATIONS OF THE FIRST YANKEE CORE

We now wish to apply the methods and information presented in Sections III and IV to the actual Yankee core design which was briefly discussed in Section II. The factor $R$ has been calculated for the hot, clean, no power Yankee core with 24 control rods inserted using both one and two-dimensional techniques. From Table 1 , we note that an $R$ of $1 / 1.1264$ - .888 would just bring the core to $k=1$. To provide an additional $3 \%$ shutdown, an $R=.97 / 1.1264=.861$ is required.

One-dimensional calculations (using $\Sigma_{f C R}=.08 \mathrm{~cm}^{-1}$ ) are summarized in Table 9 for various arrangements of fully inserted Yankee control rods (see the group numbering pattern of Figure 10, with its shading of the regions assigned to each ring of control.) The 32 rod case is included for reference only, as there are only 24 mechantsms available. One can see from Table 9 that the 24 rods provide a margin of approximately 3\% beyond the $R=.861$ required, but these one-dimensional numbers are only to be taken as an approximate indication of the actual situation. The remaining cases in Table 9 represent the successive removal of rod groups from the Yankee core and have been studied as the initial step in a study of rod programming in this core. More accurate numbers, especially for the max/average power, would have to be obtained using two-dimensional techniques. These max/average values completely ignore such things as local peaking effects and are to be considered only relative to each other. 


\section{TABLE 9}

One-Dimensional Calculations of Yankee Control

$$
\left(\Sigma_{\mathrm{fCR}}=.08 \mathrm{~cm}^{-1}\right)
$$

Rod Groups Inserted

$\mathrm{R} \quad$ Max/Average Power

32 rods

$24(1,2,3,4,5,6)$

$16(1,2,3,4,5)$

$12(1,2,3,4)$

$8(1,2,3)$

$4(1,2)$

2(1)

0
.810

.835

.887

.922

.939

.970

.978

1.000
1.55

1.26

1.34

1.47

1.40

1.44

1.45

1.93

Table 10 summarizes the results obtained to date using the two-dimensional PDQ code (with $\Sigma_{f C R}=.12 \mathrm{~cm}^{-1}$ ) on this core. The calculations as they stand show that there is sufficient control with 24 rods and $8 \mathrm{zr}$ followers $(R \leq .861$ ). However, if the reactivity or control worth calculations prove overoptimistic, one can obtain an additional 1\% shutdown by using steel instead of $\mathrm{Zr}$ fillers in the outer 8 slots. Indeed, the 32 rod calculations show that steel fillers with various amounts of natural or enriched boron could provide up to $4 \%$ additional shutdown. It would not be desirable to actually polson fillers, if their use can be avoided, because they would have to be removed sometime before the end of the core life if the reactor is to attain its full lifetime. In addition, the use of poison fillers may cause an undesirable (from the standpoint of power extraction from the core) depression of power density in the outer region. 
The other calculation results given in Table 10 show the loss of shutdown when one of the highest worth rods is stuck out (1.0\%), and the effect of a rearrangement of the 24 rods and $8 \mathrm{zr}$ fillers. This rearranged case seems to be an improvement over the design so far assumed (compare Figures 1 and 11 ).

\section{TABLE 10}

Two-Dimensional Calculations of Yankee Control

$$
\left(\Sigma_{\mathrm{fCR}}=.12 \mathrm{~cm}^{-1}\right)
$$

\begin{tabular}{|c|c|c|}
\hline Rods Inserted & $\mathrm{R}$ & Max/Average Power \\
\hline 32 rods & .817 & 2.15 \\
\hline $24,8 \mathrm{zr}$ fillers & .853 & 2.01 \\
\hline 24,8 ss fillers & .844 & 1.70 \\
\hline $\begin{array}{l}\text { 23, } 9 \text { Zr fillers } \\
\text { (one central rod } \\
\text { stuck out) }\end{array}$ & .862 & 2.84 \\
\hline $\begin{array}{l}\text { 2L, } 8 \mathrm{Zr} \text { fillers } \\
\text { rearranged } \\
\text { (see Figure 11) }\end{array}$ & .847 & 1.65 \\
\hline $32 \mathrm{Zr}$ fillers & 1.000 & 2.36 \\
\hline
\end{tabular}




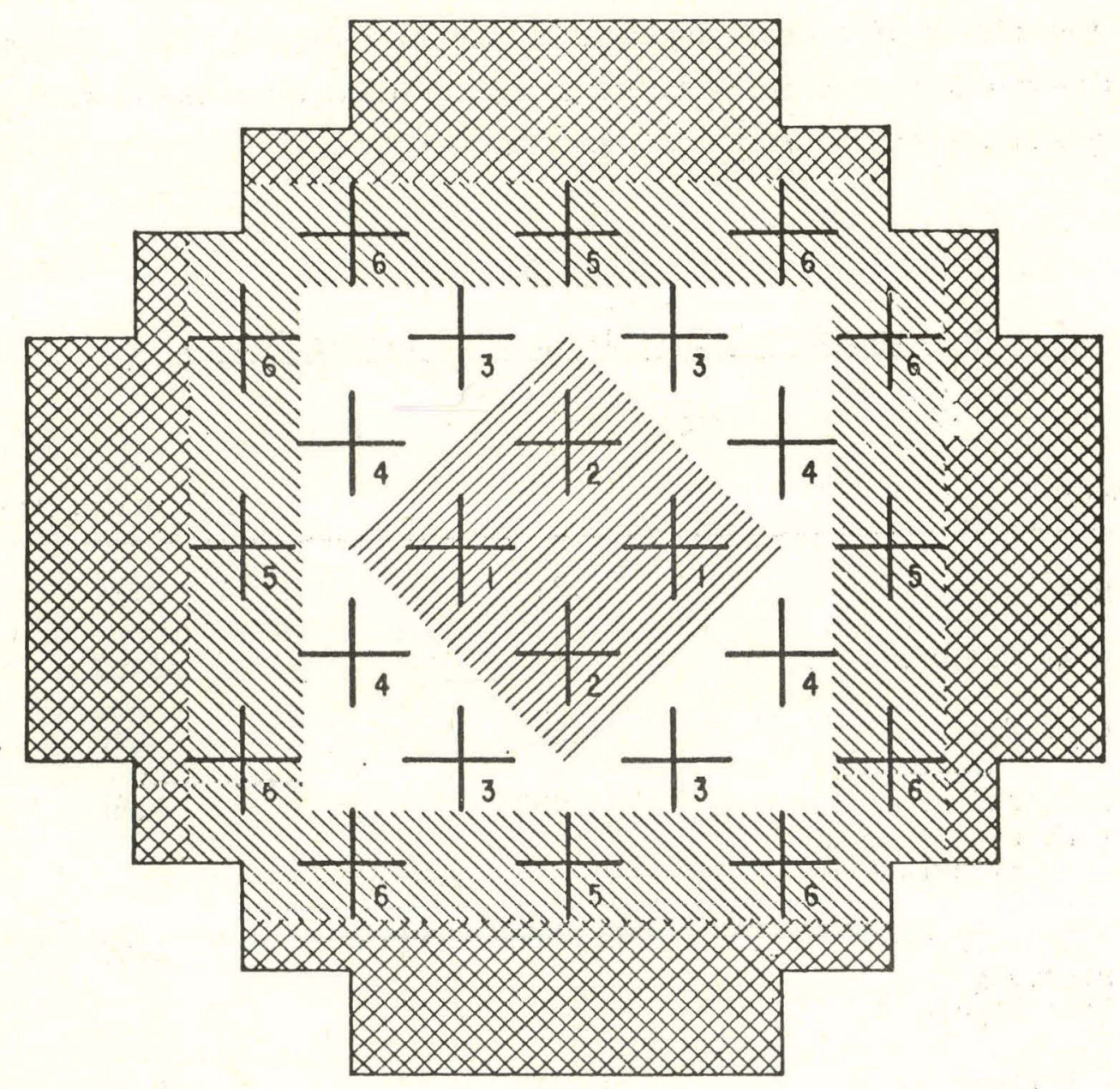

CORE REGIONS IVIIIIA $2 \square \quad 3$ MIII 4 (4)

Figure 10

YANKRE CONTROL ROD GROUPS 


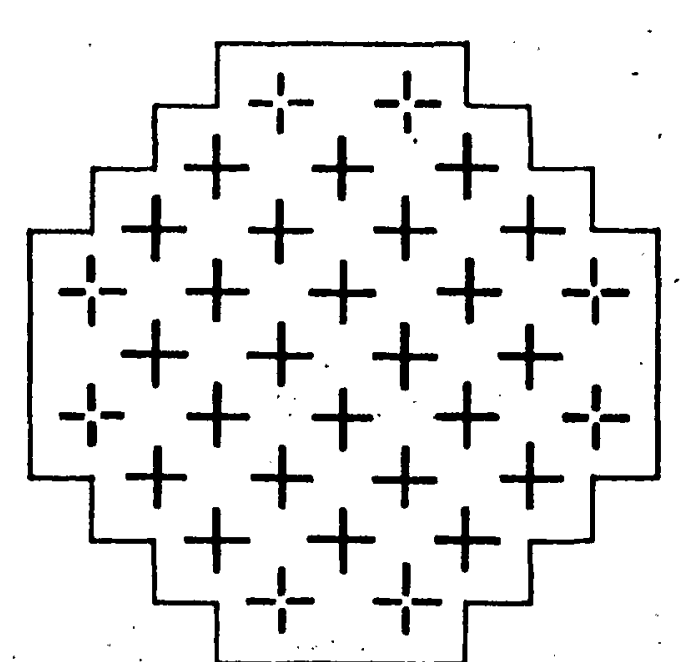

"NORMAL" PATTERN

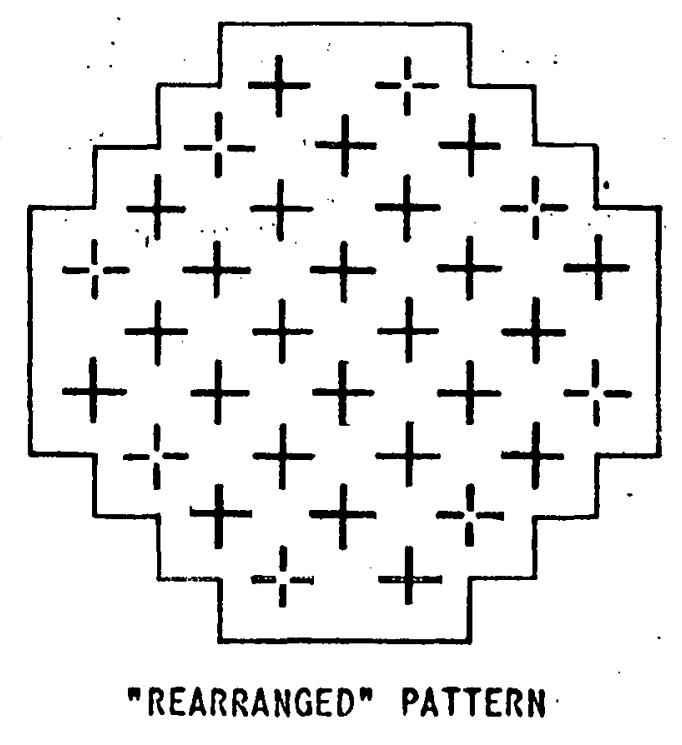

$$
\begin{aligned}
& \text { - CONTROL ROD LOCATION } \\
& \text { - }
\end{aligned}
$$

FIGURE 11 ALTERNATE ARRANGEMENTS OF 24 CONTROL RODS AND 8 Zr FILLERS III YANKEE FIRST CORE

$-41-$ 
ACKNOWLEDGEMENTS

The author would like to express his gratitude to Dr. Perry W. Davison, and his staff of the Westinghouse Reactor Evaluation Center, whose untiring efforts yielded the experimental information reported in Section IV of this report. A number of people have aided in the detailed calculations; these include Betty S. Hemmerle, V. Grob, and J. Noonan. In addition, Mr. J. E. Howard, of the Yankee Atomic Electric Company, made valuable contributions to both the experimental and calculational work reported here: 
APPENDIX I

DERIVATION OF BQUATION 18

Le.t a non-scattering absorbing slab of thickness $2 b$ (centered at $x=0$ ) be surrounded by a non-capturing medium on both sides. In terms of the flux and current into the surface, the total current of neutrons into the slab on the two faces is 10 : *

$$
\begin{aligned}
& \underset{\text { entering current }}{\text { at lethargy } u}=\frac{\emptyset(b)+\varnothing(-b)}{4}+\frac{D}{2}\left\{\left.\frac{\partial \emptyset}{\partial x}\right|_{b}-\left.\frac{\partial \phi}{\partial x}\right|_{-b}\right\} \\
& =\frac{\varnothing(b)}{2}+\left.D \frac{\partial \emptyset}{\partial x}\right|_{b} \text {, using symmetry }
\end{aligned}
$$

Introduce two quantities, $F_{0}(u)$ and $F_{1}(u)$, which are the capture . fractions of the zeroth and first Legendre coefficients of the angular flux. In other words, $F_{0}$ is the ratio of captured to entering neutrons where the entering neutrons are isotropically distributed. $F_{1}$ is the capture fraction for entering neutrons distributed linearly in the cosine of the polar angle ( $\partial \phi / \partial x$ in diffusion theory).

We can use these capture fractions in equation $\mathrm{A}-1$. to get the total number of neutrons captured at lethargy u per unit time.

$$
\underset{\text { lethargy } u}{\text { capture rate at }}=\frac{1}{2} \phi \text { (b) } F_{0}+\left.D \frac{\partial \phi}{\partial x}\right|_{b} F_{I} \text {. }
$$

But, if neutrons are to be conserved, this must also equal the sum of the net currents $(D \partial \phi / \partial x)$ entering at each face:

$$
-\left.D \frac{\partial \emptyset}{\partial x}\right|_{-b}+\left.D \frac{\partial \phi}{\partial x}\right|_{b}=\left.2 D \frac{\partial \phi}{\partial x}\right|_{b}=\frac{1}{2} \emptyset(b) F_{0}+\left.D \frac{\partial \phi}{\partial x}\right|_{b} F_{1}
$$

z

The $D$ is here a core constant. 
This yields a relationship between $\emptyset(b)$ and $D \partial \emptyset /\left.\partial x\right|_{b}$. If we define $\alpha$ as the ratio of current to flux at b:

$$
\alpha(u)=\frac{\left.D \frac{\partial \emptyset}{\partial x}\right|_{b}}{\emptyset(b)}=\frac{F_{0}(u)}{2\left[2-F_{1}(u)\right]}
$$

In equation $A-4$, the $u$ dependence of $F_{0}$ and $F_{1}$, and hence of $\alpha$, has. been introduced because $F_{0}$ and $F_{I}$ are obtained from the cross sections of the absorber slab. Our next step is to calculate $F_{0}$ and $F_{1}$.

$F_{n}$ is defined as the capture fraction of a flux which has an entering angular distribution of $\mu^{n}$ ( $\mu$ is the cosine of the angle between the neutron's entering path and the normal to the surface). A neutron at angle $\cos ^{-1} \mu$ travels a distance $2 b \Sigma_{a} / \mu$ mean free paths to get through the.slab, so that the capture fraction will be: .

$$
\begin{aligned}
F_{n} . & =1-\frac{\text { neutrons escaping }}{\text { neutrons entering }} \\
& =1-\frac{\int_{0}^{1} \mu^{n} \exp \left[-\frac{\Sigma_{a} 2 b}{\mu}\right] \mu d \mu}{\int_{0}^{1} \mu^{n} \mu d \mu} \\
& =1-(n+2) E_{31+3} \cdot\left(2 b \Sigma_{d}\right)
\end{aligned}
$$

In equation $A-5, E_{\ell}(k)$ is the Placzek function of order $\ell / 6$. Substitution of equation $A-5$ into $A-4$ yields equation 18 of the text. 
We assume the same geometry as that of Appendix 1: region 1 is the absorbing slab, region 2 is the surrounding moderator: Assume a unit source in region 2 so that the diffusion equations become:

$$
\begin{aligned}
& D_{1} \nabla^{2} \emptyset_{1}-\Sigma_{1} \emptyset_{1}=0 ;\left.\frac{\partial \emptyset_{1}}{\partial x}\right|_{b}=0 \\
& \therefore \phi_{1}=\mathrm{B} \cosh x_{I} \mathrm{x} ; \quad x=\sqrt{\frac{\Sigma}{D}} \\
& \mathrm{D}_{2} \nabla^{2} \phi_{2}-\Sigma_{2} \phi_{2}+1=0 ; \quad \underset{x \rightarrow \infty}{\lim } \emptyset \text { finite } \\
& \emptyset_{2}=\frac{1}{\Sigma_{2}}=A e^{-x} 2^{x}
\end{aligned}
$$

Equality of flux and current at $x=b$ determine the arbitrary constants $A$ and $B$.

$$
\begin{aligned}
& \phi_{1}(b)=\phi_{2}(b) \\
& \left.D_{1} \frac{d \phi_{1}}{d x}\right|_{b}=\left.D_{2} \frac{d \emptyset_{2}}{d x}\right|_{b} \\
& \therefore \phi_{2}(x)=\frac{1}{\Sigma_{2}}\left[1-\frac{e^{-x_{2} x}}{e^{-x_{2} b}}\left(1+\frac{D_{2} x_{2}}{D_{1} x_{1}} \operatorname{coth} x_{1} b\right)^{-1}\right]
\end{aligned}
$$


Since $\alpha$ was defined as the ratio of current to flux, we have:

$$
\alpha=\frac{\left.\mathrm{D}_{2} \frac{\mathrm{d} \phi_{2}}{\mathrm{dx}}\right|_{\mathrm{b}}}{\phi_{2}(\mathrm{~b})}=\frac{\mathrm{D}_{2} x_{2}\left(1+\frac{\mathrm{D}_{2} x_{2}}{\mathrm{D}_{1} x_{1}} \operatorname{coth} x_{1} \mathrm{~b}\right)^{-1}}{1-\left(1+\frac{\mathrm{D}_{2} x_{2}}{\mathrm{D}_{1} x_{1}} \operatorname{coth} x_{1} \mathrm{~b}\right)^{-1}}
$$

$$
\therefore \quad \alpha \quad D_{1} x_{1} \tanh x_{1} b \quad \therefore \quad \therefore \quad(A-12)
$$

If one assumes $D_{1}=1$ and $x=\sqrt{\Sigma / D}$, equation $A-12$ is identical with 20. 


\section{BIBLIOGRAPHY}

1. G. Bilodeau, W. Cadwell, J. Dorsey, J. Fairey, R. Varga, "PDQ - An IBM-704 Code to Solve the Two-Dimensional Few-Group Neutron-Diffusion Equations", WAPD-TM-70 (1957).

2. A. Henry, TID-7532 (Pt. 1) Reactor Control Meeting, p. 3 (1957).

3. R. Halgas and M. Bender, "Comparison of Theoretical Techniques in the Analysis of a Slab Reactor", WAPD-T-539, (1957).

4. D. Hughes and R. Schwartz, "Neutron Cross Sections", 2nd Edition BNL-325 (1958). .

5. S. Stein, "Resonance Capture in Heterogeneous Systems", WAPD-139 (1955).

6. Case, F. de Hoffman, G. Placzek, IIntroduction to the Theory of Neutron Diffusion", v. 1, p. 153, Los Alamos (1953).

7. H. Bohl, Jr., E. Gelbard, G. Ryan, "Fast Neutron Spectrum Code for the IBM-704", WAPD-TM-72 (1957).

8. R. J. Neuhold, Trans. of the Am. Nuclear Society 1, no. 2, p. $\mathrm{H}_{4} \mathrm{O}(1958)$.

9. 0. Marlowe, C. Saalbach, L. Culpepper, D. McCarty, "WANDA - A One-Dimensional Few Group Diffusion Equation Code for the IBM-704", WAPD-TM-28 (1956).

10. S. Glasstone and M. Edlund, "The Elements of Nuclear Reactor Theory", p. 99, Van Nostrand, New York (1952). 